\title{
Sobre el anarquismo en la historiografía de la izquierda argentina
}

\section{Un recorrido a través de huelgas, bombas, almas bellas, dandys y anarcadémicos}

"The present revival of interest in anarchism is a curious and at first sight unexpected phenomenon. Even ten years ago it would have seemed in the highest degree unlikely. At that time anarchism, both as a movement and as an ideology, looked like a chapter in the development of the modern revolutionary and labour movements that had been definitely closed. As a movement it seemed to belong to the pre-industrial period, and in any case to the era before the First World War and the October revolution, except in Spain, where it can hardly be said to have survived the Civil War of 1936-9. One might say that it disappeared with the kings and emperors whom its militants had so often tried to assassinate. Nothing seemed to be able to halt, or even to slow down, its rapid and inevitable decline, even in those parts of the world in which it had once constituted a major political force in France, Italy, Latin America [...] and somehow this reminder of a long-lost era of bohemians, rebels and avant-garde seemed only too characteristic. [...] In brief, the main appeal of anarchism was emotional and not intellectual".

Eric Hobsbawm, Revolutionaries, 1973.

"From each as they choose, to each as they are chosen". Robert Nozick, Anarchy, state, and utopia, 1974.

A diferencia de lo que sucedió con otras familias de la izquierda, el movimiento anarquista argentino ha despertado un temprano y cuantioso interés en investigaciones de muchos países del mundo. ${ }^{1}$ Este interés ha resultado proporcional a su notable magnitud, sólo comparable con algunos otros pocos países, como Italia, España y los Estados Unidos. Por esto, detenerse en las miradas que ha recibido este movimiento político funciona de manera ilustrativa en relación con lo sucedido en otras latitudes

* Consejo Nacional de Investigaciones Científicas y Técnicas (CONICET) - Centro de Documentación e Investigación de la Cultura de Izquierdas (CeDInCl). https://orcid.org/0000-0001-9058-9573

1 En este artículo sigo las indicaciones sugeridas por dos textos que tuve el privilegio de compilar: Lucio Mafud, "Las representaciones del anarquismo en la cultura audiovisual argentina, 1909-2016" y Laura Fernández Cordero, "Historias de un siglo largo", ambos en: El anarquismo argentino: Bibliografía, hemerografía y fondos de archivo, Buenos Aires, CeDInCl-Anarres-Terramar-Tupac, 2018. En relación con los trabajos citados de Laura Fernández Cordero, estas páginas se proponen continuarlos intentando trazar vínculos entre la bibliografía específica sobre el tema y la historiografía sobre la izquierda local en general sin atribuirle a ella claro los errores aquí presentes. y en la izquierda local en general.

Como documentó recientemente el historiador del cine argentino Lucio Mafud, los medios audiovisuales permiten periodizar distintas imágenes sociales sobre el anarquismo en el país, que en general oscilaron entre identificar este movimiento con la violencia vindicadora o con un alma bella quijotesca. Con este trabajo realizado, resulta ahora posible pensar que estas imágenes dialogaron de diferentes maneras con los intereses historiográficos que suscitó este movimiento político a lo largo del siglo $\mathrm{XX}$.

Las páginas siguientes interrogan las perspectivas historiográficas que se interesaron en la experiencia libertaria argentina para determinar los principales ejes de discusión. Su objetivo principal es comprender estas obras en un esquema historiográfico más amplio sobre las izquierdas en general. En este sentido, identificaremos tres momentos generales dentro de los cuales 
luego incluiremos las principales líneas de interpretación.

En un primer momento historiográfico, la pregunta rectora compartida por las interpretaciones iniciáticas se enfocó en la relación de las distintas tradiciones políticas con el movimiento obrero. Sobre todo, se desarrolló en los primeros textos que desde el socialismo y el propio anarquismo pretendieron establecer su identidad política dentro del arco de las familias de la izquierda en Argentina a partir de la década de 1920. Dos décadas después esta pregunta continuaba, ya no en relación con el proceso ruso y la emergencia del comunismo, sino sobre todo enfocada en reconstruir una tradición gremial libre frente al peronismo. También este tipo de indagación que tomaba como objeto de estudio el movimiento obrero organizado fue del que partieron los primeros historiadores profesionales que abordaron el tema a principios de la década de 1980 .

En segundo lugar, las interpretaciones más difundidas que han relativizado la importancia del estudio de las izquierdas buscaron un objeto de estudio menos politizado, bajo el argumento de que, al menos desde un punto de vista económico y político-institucional, los sectores populares fueron sobre todo moderados, procuraron integrarse a un mercado de trabajo relativamente exitoso y su vínculo con el movimiento obrero organizado de izquierda se correspondería con momentos puntuales y/o meramente pintorescos. En general, esta línea fue la que se estableció en el marco de la profesionalización de la tarea historiográfica con la vuelta de la democracia, ocupó los principales espacios de gestión académica y buscó diferenciarse del primer conjunto de trabajos recién mencionado a los que les reconocía un núcleo de problemas en común.

Finalmente, en tercer lugar, el conjunto de interpretaciones más reciente se interesa sobre todo por un movimiento político como el anarquismo en búsqueda de continuidades teóricas y prácticas de diversas luchas por los derechos individuales y formas de organización autónomas y anti-jerárquicas.

Dentro de estos tres momentos, las siguientes páginas inscriben la historiografía sobre el anarquismo en una durée más amplia sobre la izquierda local a través de instituciones y revistas, aunque poniendo sobre todo el foco en los libros producidos sobre anarquismo. Organizamos el recorrido de la siguiente manera:

(a) Las primeras obras historiográficas anarquistas y socialistas destinadas a conformar un corpus y trazar las identidades de sus respectivas tradiciones políticas concluido el período de reorganización posterior a la Revolución rusa;

(b) los textos historiográficos sobre la historia del movimiento obrero local que desde el socialismo, el anarquismo, el sindicalismo y el comunismo observaban el nuevo vínculo entre sindicatos y peronismo;

(c) la reconfiguración de una cultura editorial vinculada a la llamada nueva izquierda que entre los sesenta y los setenta trazó diversas tradiciones con gestos de continuidad y ruptura en relación al anarquismo y su temprano vínculo con el movimiento obrero;

(d) los primeros estudios universitarios sobre la conformación sindical del peronismo, que se enfocaban sobre todo en el movimiento gremial posterior a 1930;

(e) el desarrollo de investigaciones de largo aliento sobre el anarquismo local desde universidades del exterior;

(f) la aparición de los trabajos universitarios sobre el movimiento obrero argentino;

(g) los trabajos de los historiadores nucleados en el Programa de Estudios de Historia Económica y Social Americana (PEHESA) y su crítica a los estudios marxistas sobre el movimiento obrero;

(h) el proyecto de la revista Entrepasados (Buenos Aires, 1991-2012) y su materialización en el libro Anarquistas de Juan Suriano;

(i) Los primeros estudios desde universidades locales y del exterior sobre los vínculos del anarquismo con la educación, el feminismo y la literatura;

(j) la conformación del Centro de Documentación e Investigación de la Cultura de Izquierdas (CeDlnCl) como centro de documentación e investigación de la cultura de izquierda desde la historia intelectual;

(k) la aparición de nuevos grupos de investigación que surgieron desde el trotskismo con el objetivo de relanzar una historia marxista enfocada en las nociones de clase y trabajadores; y

(L) una nueva producción académica post 2001, interesada por distintas luchas sociales y las experiencias de organización horizontales y cooperativas.

Insistimos, en relación con este esquema, a continuación nos centraremos sobre todo en la producción de largo aliento sobre anarquismo que se materializó en formato libro. 
Vindicadores, trabajadores,
almas bellas y anarcadémicos

(a) Muy temprano, en 1894, cuando apenas el movimiento anarquista local había editado unos diez periódicos efímeros y tan sólo un par de folletos marginales a lo que, sin embargo, deben sumarse como hechos significativos el intento de asesinato de Julio Argentino Roca durante su primera presidencia y la creciente actividad huelguística, se publicaron en Buenos Aires y en Córdoba dos prospectos que alertaban frente al miedo al anarquismo que ya se hacía presente en las metrópolis europeas: "El mal que aflige a Europa hoy será mañana también el mal nuestro, si no lo prevenimos a tiempo", vaticinaban con temor. ${ }^{2}$

Esta mirada tuvo continuidad no sólo en la legislación represiva dictada en 1902 ("Ley de residencia") y 1910 ("Ley de defensa social"), sino también en las noticias de los grandes periódicos y los primeros films ensayados en la Argentina, que reprodujeron una y otra vez las noticias más aterradoras sobre el anarquismo expropiador, vindicador y bandolero, sus atentados y sus bombas. Fuera de las referencias internas del propio movimiento, los matices a esta mirada también existieron, pero tuvieron una propagación dificultosa en los medios y las construcciones históricas. ${ }^{3}$ Por el contrario, la imagen literalmente anarquizante nunca resultó inocente, y funcionó destinada a justificar directa o indirectamente las primeras grandes represiones policiales, militares y para-militares sucedidas en el país. Sin dudas, contó con un notable éxito que sorprendentemente aún hoy en día vincula al anarquismo con bombas e incluso todavía encontramos ilustrando las tapas de libros de reconocidos investigadores

2 Tras la noticia del asesinato del presidente francés Marie François Sadi Carnot por el militante anarquista Sante Geronimo Caserio, estos folletos reaccionaron desde la religión y el derecho penal frente a los "peligros" de la posible llegada del anarquismo. Entre ambos propusieron la educación religiosa, la pena de muerte y la deportación como buenas soluciones para tener en cuenta en el futuro. Ver: Cornelio Moyano Gacitúa, C., Notas de filosofía penal sobre el anarquismo, Córdoba, Imprenta La Patria, 1894; la cita corresponde a: José María Cabezón, Progreso, anarquismo, cristianismo, Buenos Aires, Tipografía Salesiana del Colegio Pío IX, 1894, p. 18. Como muestra Zaragoza Ruvira, es a partir de este mismo año cuando las embajadas de Francia y Argentina comenzaron a intercambiar informes sobre "esta clase de malhechores". Ver: Gonzalo Zaragoza Ruvira, Anarquismo argentino (1876-1902), Madrid, Ediciones de la Torre, 1996

3 En esta dirección, probablemente, el documento más conocido sea la nota aparecida en el 1900 en Caras y Caretas que concluía: "Los anarquistas del Plata rechazaban la lucha política, teniendo la convicción de que el Estado, cuando las circunstancias de conservación se lo mandas, otorga la mejora que impone seriamente, y aseguran que van a la revolución social, la que según el criterio de los referidos bakunianos se hará igual hoy que mañana, cuando los cerebros hayan evolucionado lo suficiente y los prejuicios se hayan descartado en parte, que es a lo que tienden en su propaganda filosófica, combatiendo al mismo tiempo el alcoholismo, la haraganería y el delito. Hay que confesar que, si todos los anarquistas del Plata opinan de esta manera, no hay motivos para que sean molestados por la policía, y resultan tan inofensivos como los que creen en la metempsicosis", "El anarquismo en el Río de la Plata", Caras y Caretas, $n^{\circ} 97,11 / 4 / 1900$. sobre el tema. ${ }^{4}$

Dentro de la izquierda, desde un principio el anarquismo ya había logrado una caracterización duradera por parte de los propios Marx y Engels en sus opúsculos contra Bakunin, que la socialdemocracia se empeñó en traducir y difundir a fines del siglo XIX y comienzos del siglo XX, sobre todo en aquellas naciones, como España, Francia e Italia, donde el anarquismo se había asentado tempranamente en el movimiento obrero. En Argentina, socialistas como Germán Avé Lallemant, Juan B. Justo y José Ingenieros, entre otros, colaboraron en instalar la mirada de la Segunda Internacional presente también en el epígrafe y la obra de Hobsbawm, según la cual el anarquismo era considerado como un movimiento característico de los países de escaso desarrollo industrial, condiciones que habrían dado lugar a un artesanado aún semiproletarizado o a una clase trabajadora apenas embrionaria, "pasional" y "atrasada". Aún hoy ésta es la mirada habitual que persiste en la izquierda política y en buena medida también en la historiografía marxista.

Entre persecuciones y desidias, mientras tanto, decenas de periódicos, libros y folletos editados en el país por este enorme movimiento político se perdieron. Sólo recién en la década de mil novecientos veinte, fueron los propios militantes anarquistas quienes se convirtieron en los primeros bibliófilos, hemerófilos, archivistas e historiadores de su movimiento. Entre algunos otros, me refiero principalmente a Diego Abad de Santillán, a nivel nacional, y a Max Nettlau, en el marco internacional. Estos autores trazaron las primeras pistas historiográficas e iniciaron un género memorialístico interno al movimiento que se mantuvo por años y hasta hace muy poco tiempo. De este modo, en la década de 1920 no sólo comenzaron a conformarse los fondos documentales con los que contamos hoy en día, sino que además las principales familias políticas de la izquierda local iniciaron las "invenciones" de su tradición para seguir con Hobsbawm y propusieron sus lecturas históricas con el objetivo de estabilizar sus propias construcciones identitarias frente al cisma de reconfiguraciones que significó la Revolución rusa de 1917. Con sus propios objetivos gremiales, fueron también ellos mismos quienes plantearon y continuaron la primera gran inquietud historiográfica que compartían junto al marxismo sobre el vínculo del anarquismo con el desarrollo del movimiento obrero local. Sin embargo, con una diferencia importante respecto a la historiografía socialista: las construcciones libertarias daban otra centralidad a la agencia humana propia de los militantes y la historia aparecía mucho menos constreñida a sus determinantes económicos. ${ }^{5}$

$4 \quad$ Me refiero a la tapa del libro de divulgación de Juan Suriano editado por Capital Intelectual Auge y caída del anarquismo: Argentina 1880-1930, Buenos Aires, Capital Intelectual, 2005.

5 Si bien con anterioridad desde cada tradición se habían publicado algunos artículos y desarrollado otras formas de construcción identitaria, principalmente, las obras de mayor aliento fueron las de Diego Abad 
(b y c) De hecho, durante el primer peronismo, a la par de lo que sucedía en la historiografía, la imagen constante que vinculaba al anarquismo con la violencia y el atraso se consolidaba, pero bajo otras operaciones que lo reconocían como parte de los inicios de la lucha obrera. Sobre todo, porque en la década del cuarenta el anarquismo aparecía ante la hegemonía peronista menos como un rival que como que como un fenómeno concluido y ya alejado en el tiempo. Se trató de un proceso paulatino durante el que afloró una mirada comparativamente benévola. Al menos desde dos direcciones.

Por un lado, más allá de cualquier decisión metodológica, los acercamientos al socialismo y al anarquismo posteriores a la década del treinta fueron parte del rol que tomaron como historiadores algunos dirigentes gremiales y partidarios a partir de estos años. En buena medida, las obras socialistas y sindicalistas partieron de la necesidad de historizar, en un primer momento, el quiebre de las izquierdas con el movimiento obrero organizado, y, luego, frente al peronismo, el fin del "gremialismo libre". En relación con este problema hay que leer entonces el otro arco de trabajos desde los textos de Jacinto Oddone hasta los escritos históricos de Sebastián Marotta que durante estas décadas abordaron la historia del movimiento obrero y las izquierdas, respectivamente, desde el socialismo y el sindicalismo. ${ }^{6}$

Por otro lado, si bien a partir de 1937 distintas agrupaciones comunistas, anarquistas y socialistas compartieron plataformas primero anti-fascistas y después anti-peronistas, una nueva imagen historiográfica resultó capaz de incluir paulatinamente al anarquismo como un digno y viejo antecedente para el movimiento obrero local, con el objetivo claro de desacreditar a otros rivales políticos que hacia la década del cincuenta consideraban más vivos y desafiantes. Como señaló Lucio Mafud en su trabajo ya citado, por ejemplo, los guiones de Homero Manzi de los films Con el dedo en el gatillo (Moglia Barth, 1940) y El último payador (Pappier y Manzi, 1950) criticaban la violencia política identificada con el anarquismo al tiempo que en parte rescataban sus ideales de justicia social. De manera similar este cambio de perspectiva podía documentarse en los textos de un autor de la izquierda nacional como Jorge Abelardo Ramos o

de Santillán, por un lado, y Jacinto Oddone, por parte del socialismo. Diego Abad de Santillán y Emilio López de Arango, El anarquismo en el movimiento obrero, Barcelona, Cosmos, 1925; Diego Abad de Santillán, El movimiento anarquista en la Argentina, desde sus comienzos hasta 1910, Buenos Aires: Argonauta, 1930; Jacinto Oddone, Historia del socialismo argentino, Buenos Aires, La Vanguardia, 1934. Las construcciones identitarias y las experiencias gremiales y culturales compartidas por socialistas terceristas, anarquistas y sindicalistas revolucionarios ha sido sobre todo puesta en manifiesto y desarrollada por Andreas Doeswijk, Los anarcobolcheviques rioplatenses, Buenos Aires, CeDInCl, 2013.

6 Ver: Martín Casaretto, Historia del movimiento obrero, Buenos Aires, [s.n.], 1946; Jacinto Oddone, Gremialismo proletario argentino, Buenos Aires, La Vanguardia, 1949; Sebastián Marotta, El movimiento sindical argentino, Buenos Aires, Lacio-Calomino, 1960-1970. en un libro como el de Alberto Belloni. ${ }^{7}$ Sin embargo, al recorrer la producción del conjunto de autores vinculados a la izquierda nacional, resulta claro que Puiggrós, Spilimbergo, Aberlardo Ramos y Hernández Arregui tenían como rivales más directos a lo que llamaban "socialismo cipayo" y se presentaban ante las masas peronistas como una izquierda que estaba en las antípodas del socialismo liberal.8 De este modo, estas obras además discutían con los nuevos estudios que desde la universidad comenzaban a buscar una explicación de la emergencia del movimiento peronista y se enfocaban sobre todo en el sindicalismo de los treinta y los cuarenta. ${ }^{9}$

Poco después, este tipo de lecturas capaces de incluir al anarquismo dentro de los orígenes del movimiento obrero argentino con el fin de apropiarse de cierta temprana épica huelguística y sumarlo a una revolución general se cristalizó claramente en varias obras, entre las cuales el film La hora de los hornos (1968) resulta ineludible. En esos años, sobre todo fue Osvaldo Bayer quien logró hilvanar al anarquismo como antecedente político y cultural de varios procesos históricos que podían ser leídos de diferentes maneras, tanto como una justificación de la violencia política al calor del juicio revolucionario a Aramburu, por su Severino Di Giovanni, como también, en general, como un antecedente de la militancia sacrificada y pura, incapaz de contaminarse con intereses

7 ''La emancipación de los trabajadores ha de ser obras de ellos mismos'. Después de cuarenta años esta frase es repetida por el Coronel Perón será la convergencia del pensamiento revolucionario socialista con el movimiento nacional que se inicia en 1945. Coincidencias semejantes se analizarán en el mismo libro más adelante". Más adelante: "Reivindica entre las grandes tradiciones de la clase trabajadora también a los militantes heroicos y anónimos de las horas primeras, a esos combatientes sindicalistas, anarquistas, socialistas y comunistas, que más allá de sus orientaciones partidarias echaron las bases iniciales de la organización gremial [...]. Todos ellos precedieron al nacimiento del sindicalismo peronista". Alberto Belloni, Del anarquismo al peronismo: historia del movimiento obrero argentino, Buenos Aires, Peña Lillo, 1960, p. 16 y 72. También puede leerse en esta misma dirección: Alfredo López, Historia del movimiento social y la clase obrera argentina, Buenos Aires, Programa, 1971. Con esto no quiero decir que se trate de un lugar aceptado ni mucho menos. Por lo general, otros autores de la izquierda nacional de estos años también identificaron, como se hizo históricamente del el Partido Socialista, al anarquismo con un movimiento obrero infantil, pasional, "primitivo", literalmente "anarquizado". Con la diferencia de que ahora también solían identificarlo despectivamente con cierta bohemia estética de moda entre algunos ejemplares de clases acomodadas. Ver, por ejemplo: Juan José Hernández Arregui, Imperialismo y cultura, Buenos Aires, Amerindia, 1957; o de manera similar en su vertiente más marxista: Rodolfo Puiggrós, Las izquierdas y el problema nacional, Buenos Aires, Jorge Álvarez, 1967.

8 Rodolfo Puiggrós, Historia crítica de los partidos políticos argentinos Buenos Aires, Argumentos, 1956; Jorge Abelardo Ramos, El partido comunista en la política argentina, Buenos Aires, Coyoacán, 1962; José Spilimbergo, El socialismo en Argentina, Buenos Aires, Mar dulce, 1969.

9 Gino Germani, Política y sociedad en una época de transición, Buenos Aires, Paidós, 1963; Miguel Murmis y Juan Carlos Portantiero, Estudios sobre los orígenes del peronismo, Buenos Aires, Siglo XXI, 1971. En relación con el tema en cuestión, principalmente entre estos trabajos trazaron entonces una nueva pregunta rectora sobre el movimiento obrero que ya se desplazaba cronológicamente y contribuía a generar un interés por el sindicalismo revolucionario desde un punto de vista en buena medida teleológico. Ver también: Hiroshi Matsushita, Movimiento obrero argentino: 1930-1945, Buenos Aires, Siglo Veinte, [1983]. 
económicos y poderes políticos. Como señaló por ejemplo Juan Suriano, entre los sesenta y los setenta las relecturas políticas de los anarquismos quedaron sujetas a diversas interpretaciones en búsquedas de genealogías, quiebres y continuidades. ${ }^{10}$

El auge de estos textos de amplio alcance que se convertirían en parte de una nueva cultura de izquierda comenzó en los años que fueron entre 1968 y 1974, cuando se sucedieron el best-seller de Godio un autor entonces vinculado al Partido Comunista Revolucionario, PCR sobre la Semana trágica de enero de 1919 que fue publicado en 1971, el libro de David Viñas del mismo año y los libros de Osvaldo Bayer sobre Di Giovanni y las huelgas patagónicas." Vale la pena aclarar que en gran medida estos estudios compartían además una tesis en común y apuntaban a destacar que el límite de este movimiento político central de principio de siglo había estado en su falta de directrices ideológicas claras e implícitamente entonces en la ausencia de una dirección política. ${ }^{12}$ Las intenciones marcadamente militantes y/o normativas de buena parte de estos textos fueron inmediatamente criticadas por el historiador británico David Rock, quien, además de relativizar el protagonismo anarquista en las huelgas de enero de 1919, señalaba que el objetivo implícito de Godio era "el de proveer un esquema crítico y por lo tanto un programa para la 'lucha armada' de las masas de la clase trabajadora contra el capitalismo y el Estado que lo apoya".13

Con todo, a través de estas obras el anarquismo comenzó entonces a conocerse por episodios que lo excedían en su importancia histórica y se materializaba en grandes ventas que alcanzaron a un público amplio desde extensas notas en una revista que entonces alcanzaba grandes tirajes como Todo es historia (Buenos Aires, 1967-) y los populares fascículos del Centro Editor de América Latina algunos de ellos dentro de colecciones dirigidas por Alberto J. Pla, hasta los best-sellers antes señalados de Bayer, Viñas y Godio. ${ }^{14} \mathrm{~A}$ esto se sumaba que

10 Ver en Juan Suriano, Anarquistas (1890-1910), Buenos Aires, Manantial, 2001, p. 25. Desde otra perspectiva, sobre la obra de Bayer Omar Acha dedicó un capítulo a analizar algunas cuestiones de su intervención historiográfica: Historia crítica de la historiografía argentina, Vol. 1: Las izquierdas en el siglo XX, Buenos Aires, Prometeo, 2009.

11 David Viñas, De los montoneros a los anarquistas, Buenos Aires, Carlos Pérez, 1971; Julio Godio, El movimiento obrero y la cuestión nacional, Buenos Aires, Erasmo, 1972; Julio Godio, La semana trágica de 1919, Buenos Aires, Gránica, 1972; Osvaldo Bayer, Severino Di Giovanni, Buenos Aires, Galerna, 1970; Osvaldo Bayer, Los vengadores de la Patagonia trágica, Buenos Aires, Galerna, 1974.

12 Para un ensayo sobre posibles vínculos entre anarquismo y nueva izquierda a nivel internacional, ver: Anthony Arblaster, El anarquismo y la nueva izquierda, Madrid, Zero, 1974.

13 David Rock, "La semana trágica y los usos de la historia", Desarrollo económico, n. ${ }^{\circ} 45,1972$, pp. 185-191.

14 Se sucedieron varios artículos: Osvaldo Bayer, "Radowitzky: ¿mártir o asesino?", Todo es Historia, $n^{\circ} 4$, 1967; Nicolás Babini, "La Semana Trágica", Todo es Historia, n 5, 1967; Osvaldo Bayer, "Los anarquistas expropiadores", Todo es Historia, 1970; Jorge Larroca, "Gori, un anarquista en Buenos Aires", Todo Es Historia, n 47, 1971; Plácido Grela, "El movimiento obrero en Rosario", Todo es Historia, n 49, 1971; Juan Carlos Vedoya, "Primero de Mayo. Ayer y Hoy", Todo es Historia, n además, entre 1950 y 1976, también grandes ventas de editoriales libertarias como Américalee y Proyección colaboraron con esta recuperación histórica. ${ }^{15}$ De este modo, episodios históricos como la llamada Semana trágica de enero de 1919, las huelgas de La Forestal entre 1919 y 1921, el film Quebracho (Wullicher, 1974) y la Patagonia Rebelde (Olivera, 1974) en conjunción con las figuras de los vindicadores Radowitzky, Wilckens y Di Giovanni se hacían reconocidas y apreciadas por un público masivo. De hecho, a través de esta serie de dispositivos culturales, estos episodios y estas figuras pasaban a formar parte de la cultura de izquierdas de los años sesenta y setenta. ${ }^{16}$

Como Hobsbawm reconocía tempranamente en otra escala, dentro de estas nuevas representaciones históricas los enfoques biográficos y autobiográficos adquirieron una gran centralidad en virtud de la fascinación provocada por muchas de estas vidas intensísimas de militancia que se desarrollaron entre viajes, exilios, libros, persecuciones, huelgas, prisiones, acciones clandestinas, encuentros gremiales, manifestaciones, guerras, tiroteos, rescates, traducciones, imprentas, ediciones, amores, torturas, polémicas... De hecho, esta línea interpretativa se mostró como un modo perdurable de iluminar la militancia libertaria y nunca dejó de resultar interesante y llamativa. Por lo que en esta dirección también fueron muchas las biografías que se escribieron desde los setenta, entre otros, sobre Juan Lazarte, Severino Di Giovanni, Florencio Sánchez, Luis Danussi, Rafael Barret, Salvadora Medina Onrrubia y Rodolfo González Pacheco, entre algunos más. ${ }^{17}$ En una dirección similar, el género

73, 1973; Fernando Quesada, "La Protesta. Una longeva voz libertaria", Todo es Historia, $n^{\circ} 82-83,1974$. Por parte del CEAL, en su colección "La historia popular" sólo entre 1971 y 1972 se sucedieron: Hugo del Campo, Los anarquistas, Buenos Aires, CEAL, 1971; Raquel Meléndez y Néstor Monteagudo, Historia del movimiento obrero, Buenos Aires, CEAL, 1971; Rafael Virasoro, La Forestal argentina, Buenos Aires, CEAL, 1971 Oscar Troncoso, Los fusilamientos de la Patagonia, Buenos Aires, CEAL; Carlos M. Echagüe, Las grandes huelgas, CEAL , 1971; Alberto Ghiraldo, La tiranía del frac.., Buenos Aires, CEAL, 1972. Más allá del enfoque sobre anarquismo, entre 1972 y 1974 Albeto Pla dirigió la colección de 110 fascículos editada por el CEAL que se tituló Historia del movimiento obrero (1972-1974), con una perspectiva global, imágenes, fuentes documentales y gran tirada.

15 Con sus propios objetivos de intervención, en esos años, por ejemplo, las editoriales de cultura libertaria Américalee y Proyección llegaron a editar alrededor de 200 títulos capaces de incluir temas teóricos e históricos diversos sobre sexualidad, el cooperativismo, un liberalismo de avanzada y la historización de diversas revueltas. Por dar sólo algunos ejemplos, el libro de Jorge Solomonoff Ideologías del movimiento obrero y conflicto social, Buenos Aires, Proyección, 1971 y los diversos trabajos de Julio Mafud alcanzaron grandes ventas y posicionamientos como best-sellers.

16 Como me señaló Lucio Mafud, en este entramado las intervenciones cinematográficas muestran colaboraciones cruzadas. Por ejemplo, Viñas aparentemente se desempeñó como asesor histórico tácito de La Patagonia Rebelde (Olivera, 1974), obviamente basada en el libro de Osvaldo Bayer quien también fue el guionista del film. Estrenada en el mismo año, el guión de Quebracho (Wullicher, 1974) posiblemente estuvo inspirado en el libro de Gastón Gori sobre la represión en La Forestal.

17 En esta dirección: Héctor Adolfo Cordero, Alberto Ghiraldo: Precusor de nuevos tiempos, Buenos Aires, Claridad, 1960; Alfredo de la Guardia, Rodolfo González Pacheco, Buenos Aires, Ediciones 
autobiográfico, lejos de agotarse en las primeras décadas del siglo, y como sucedió también en otras familias de la izquierda, los mismos militantes continuaron escribiendo y editando sus narraciones históricas desde diferentes perspectivas y distintos grados de especialización. Entre los libertarios, además de los primeros textos memorialísticos de Eduardo Gilimón, Alberto Ghiraldo y Juana Rouco Buela, gran cantidad de autores oscilaron entre la autobiografía y las memorias, como, entre otros, Elías Castelnuovo, Diego Abad de Santillán, Jacobo Maguid, Laureano Riera Díaz, Carlos Penelas, Osvaldo Escribano Cruz, Héctor Woolands, Eduardo Colombo y Ángel Cappelletti. ${ }^{18}$ Como destacó por ejemplo Hobsbawm en el texto del epígrafe, todas estas memorias suelen engrandecer los valores propios de una cotidianidad militante vinculada a grandes sucesos históricos con el fin de promover los hitos y tópicos de una tradición libertaria.

En buena medida, esta imagen sacrificial del militante persiguiendo la Idea a través de acontecimientos radicales también se mostró por demás perdurable y con el correr de las décadas identificó a la militancia anarquista como un alma bella alejada de todos los vicios partidarios de la politiquería. Estos gestos perdurables señalaban la posibilidad de una crítica radical fuertemente moral que podía justificar la violencia política y sobre todo la posibilidad de una práctica política no contaminada por intereses económicos o partidarios. Todavía hoy también algo de esto último sobrevive.

( $\mathbf{d}$ y e) Por su parte, a partir de los años sesenta, en Argentina los estudios académicos se interesaron principalmente por el movimiento gremial posterior a 1930 con el objetivo de desentrañar el fenómeno vivo del peronismo. ${ }^{19}$ De manera antagónica a la historiografía gremial recién mencionada y a la nueva divulgación enmarcada dentro de la nueva izquierda, como señalamos, los grupos que establecerían su interpretación de la historia opuesta a las construcciones marxistas y/o nacionalistas de los años setenta surgieron inicialmente de institutos externos a la universidad como el Instituto de Desarrollo Económico y Social (IDES) y el Instituto Torcuato Di Tela (ITDT). ${ }^{20}$

Culturales Argentinas, 1963; Diego Abad de Santillán-Ángel InvaldiÁngel J.Cappelletti, Juan Lazarte: Militante social, médico humanista, Rosario, Grupo Editor de Estudios Sociales, 1964; Luis Ordaz, Florencio Sánchez, Buenos Aires: CEAL, 1972; Vladimiro Muñoz, El pensamiento vivo de Barret, Buenos Aires: Rescate, 1977; Osvaldo Bayer, Severino Di Giovanni: el idealista de la violencia, Buenos Aires, Galerna, 1970 Julio Godio, El movimiento obrero y la cuestión nacional, Buenos Aires, Erasmo, 1972

18 Para una bibliografía completa, refiero al catálogo ya citado: El anarquismo argentino, op. cit.

19 Sobre todo: Gino Germani, Política y sociedad en una época de transición, Buenos Aires, Paidós, 1963; Miguel Murmis y Juan Carlos Portantiero, Estudios sobre los orígenes del peronismo, Buenos Aires, Siglo XXI, 1971. También por ejemplo desde el marxismo, Alberto Pla, Documentos para el estudio de la época peronista, Buenos Aires, Nueva Visión, 1968.

20 Los primeros trabajos publicados de Juan Carlos Torre desde el Instituto Di Tella y las entrevistas a dirigentes gremiales realizadas desde este mismo espacio por Luis Alberto Romero y Leandro Gutiérrez
En cambio, si bien se conocerían en Argentina sólo más tarde, desde las universidades del exterior, las investigaciones de Gonzalo Zaragoza Ruvira, Richard Yoast y laacov Oved comenzaron a aparecer en los primeros años de la década del setenta a partir de la reorganización y microfilmación de los fondos de Diego Abad de Santillán y de Max Nettlau disponibles en el Instituto de Historia Social de Amsterdam (IISH). ${ }^{21}$ Entre estos trabajos, el primero que logró alcance y repercusión fue publicado a finales de los setenta en Siglo XXI de México por Jorge Tula y José $M$. Aricó. El libro estaba escrito por un historiador de origen búlgaro que desde su experiencia en los kibbutz israelíes se interesaba por los inicios del movimiento obrero en uno de los países que tuvo la mayor cantidad de periódicos, gremios y militantes anarquistas. El anarquismo y el movimiento obrero (1978) de lacov Oved, nacido de una tesis defendida en la Universidad de Tel Aviv en 1974, constituyó de esta manera el mayor hito historiográfico al dimensionar claramente el movimiento, con el problema que su enfoque descriptivo y cierto encapsulamiento en el objeto de estudio le impidieron establecer un diálogo más amplio con la historia social general del país. Con todo, como bien habían podido plantear sus militantes, lo que destacaba a este movimiento político dentro de la historia del nacional, regional e internacional fue su capacidad para dirigir la organización obrera durante al menos dos décadas.

constituyeron un nuevo tipo de acercamiento al movimiento obrero que respectivamente, desde la historia económica y el registro oral abordaba un objeto de estudio más amplio. De este modo, el "Archivo Oral del Movimiento Obrero Argentino" conserva las más de cien entrevistas realizadas durante la década del setenta a, en lo que respecta a este tema, por ejemplo, Diego Abad de Santillán, Luis Danussi y Sebastián Marotta. En paralelo la conformación del Instituto de Desarrollo Económico y Social (IDES) aunó otra serie de estudios dedicados al mercado de trabajo que, sin enfocarse en la historia social, ni en la historia de las izquierdas ni del movimiento obrero, configuraría otro espacio de profesionalización disciplinaria alrededor de su revista Desarrollo económico (Buenos Aires, 1961-). Ver: Juan Carlos Torre, El proceso político interno de los sindicatos en Argentina, Buenos Aires, ITDT, 1974; y La formación del sindicalismo peronista, Buenos Aires, Legasa, 1987. Fuera de los estudios históricos, otra línea de indagación marxista fue la impulsada por el Centro de Investigación en Ciencias Sociales (CICSO), que se fundó en 1966 tras el golpe de Estado y llegó a editar con el correr de las décadas más de una treintena de estudios en formato de cuadernillos.

21 Hobart Spalding. La clase trabajadora argentina (documentos para su historia 1890-1912), Buenos Aires, Galerna, 1970; Gonzalo Zaragoza Ruvira, "Orígenes del Anarquismo en Buenos Aires. 1886-1901", Universidad de Valencia, 1972; Richard A. Yoast, The Development of Argentine Anarchism: A Socio-Ideological Analysis, Madison, The University of Wisconsin, 1975; Eric Gordon, Michael M. Hall y Hobart Spalding, "A survey of Brazilian and Argentine materials at the Internationaal Instituut voor Sociale Geschiedenis in Amsterdam", Latin American Research Review, $n^{\circ}$ 3, Vol. 8, 1974; Oved, laácov. El anarquismo y el movimiento obrero en Argentina. Buenos Aires: Siglo Veintiuno, 1978. Además de este material, estas investigaciones utilizaron fragmentariamente los intercambios diplomáticos de las embajadas británicas y francesas con la argentina. En paralelo, cabe destacar también que desde 1971 es posible rastrear una importante cantidad de trabajos de largo aliento sobre el socialismo argentino realizado desde universidades estadounidenses, a cargo de Ernest Welfhoffer, Socialism in Argentina, New York, [s.n.], 1971; Ronald Goodbury, The Argentine Socialist Party in Congress, [s.l], [s.n], 1971; Richard Walter, The Socialist Party of Argentina, 1890-1930, Austin, University of Texas, 1977. 
Por su parte, el trabajo de Zaragoza, desarrollado durante los setenta, pero publicado de manera conjunta recién en 1996, partió de pretensiones mucho más amplias. En primer lugar, trazaba una lectura que se remontaba al "socialismo utópico" local anterior a 1880, lo que ya constituía una importante novedad en la indagación realizada hasta ese momento. A partir de allí, continuaba con un minucioso recorrido por los documentos conservados, teniendo en cuenta el asociacionismo, el internacionalismo local, la organización de los tipógrafos, el itinerario de Malatesta y el incipiente movimiento obrero en la década de 1880. Sobre algunos de estos temas, aún hoy sigue siendo uno de los trabajos más detallados en su análisis. Si bien en la primera parte de la obra el foco está puesto en las organizaciones gremiales, el libro queda lejos de determinar allí su objeto. De hecho, aunque en retrospectiva puede parecer una atención breve y marginal, se dedica especialmente a reponer las interpretaciones libertarias sobre una variedad de temas, su interés por la literatura popular, el teatro social, la educación, la liberación sexual, la emancipación de la mujer y el anticlericalismo.

( $\mathbf{f}$ y g) Desde fines de los años setenta, a partir de intereses más cercanos a los de Oved, centrados en el movimiento obrero pero con una mirada mucho más amplia dirigida hacia otros problemas historiográficos vinculados a la izquierda y la historia social en general, los trabajos de Edgardo Bilsky y de Ricardo Falcón pudieron abrir otro marco de preguntas hacia un movimiento político no solamente obrero ni dogmático, aunque sí fuertemente enfocado en la historia gremial. 22 Exilados ambos en Francia, tuvieron acceso a una renovación de los estudios históricos por entonces desconocidos en la Argentina vinculados a los nombres de Robert Paris, Jean Maitron y Madeleine Rebérioux. ${ }^{23} \mathrm{~A}$ través de un minucioso trabajo documental, Bilsky volvió a otorgarle un gran protagonismo al movimiento libertario durante la llamada Semana Trágica, pero sobre todo abrió un filón de investigación

22 El proyecto tuvo una plataforma de lanzamiento en la revista editada desde el exilio Apuntes (Paris, 1979-1980) que perduró sólo tres números. En los años siguientes, este proyecto llegó a plasmarse en: Edgardo J. Bilsky, La classe ouvriere argentine face a la semaine tragique de janvier 1919, Paris, École des Hautes Études en Sciences Sociales, 1982; Ricardo Falcón, Los orígenes del movimiento obrero (1857-1899), Buenos Aires, CEAL, 1984; Edgardo J. Bilsky, La FORA y el movimiento obrero (1900-1910), Buenos Aires, CEAL, 1985; Edgardo J. Bilsky, Esbozo de historia del movimiento obrero argentino, Buenos Aires, Biblos, 1987. Desde un punto de vista común los trabajos publicados en el exterior de Ronaldo Munck no han provocado mayores referencias y discusiones: Ronald Munck, Argentina: from anarchism to Peronism, London, Zed Books, 1987.

23 Primero dirigida por Jean Maitron y luego por Madelaine Reberiéux, probablemente, la revista Le Mouvement Social (Paris, 1960-2000) haya constituido el marco de estudios que conocieron estos autores en su exilio, sin contar la enormidad de trabajos sobre el movimiento obrero que también realizaban las plataformas comunistas en Francia. Sobre los estudios en Francia con relación al movimiento obrero que deben haber tomado como referencia, ver: Roberto Ceamanos Llorens, "La historia obrera y social contemporánea en Francia a través del estudio de L'mouvement social", Anuario Colombiano de Historia Social y de la Cultura, n. ${ }^{\circ} 33,2006$, pp. 311-336. sobre estos años radicalizados que luego explotaría Doeswijk. Lamentablemente, Bilsky discontinuó su trabajo y solamente podemos vislumbrar sus preguntas e hipótesis a partir de algunos artículos y su fondo documental. Como reconocieron distintos historiadores, quizás sin un trabajo determinado que resulte de referencia, el aporte parece haber sido una enormidad de preguntas e hipótesis abiertas en un nuevo momento de renovación y profesionalización historiográfica. Por su parte, Ricardo Falcón, quien sí concluyó su doctorado en Francia, dio lugar a dos importantes libros también pioneros. Uno de ellos sobre el movimiento obrero anterior al 900 y el segundo sobre el "mundo del trabajo urbano" a principios de siglo. De manera contrapuesta a esta serie de estudios surgieron otros frentes de discusión que conformarían las líneas de indagación que se desarrollaron durante la década del noventa.

En contraposición a este proyecto, también desde principios de la década de 1980, Luis Alberto Romero, Hilda Sábato, Leandro Gutiérrez y otros historiadores comprometidos con el Programa de Estudios de Historia Económica y Social Americana (PEHESA) procuraron un corrimiento teórico de la noción de clase y movimiento obrero hacia la historia social y el uso de la categoría de "sectores populares". ${ }^{24}$ Según las tesis presentes en varios trabajos de este grupo, los vínculos entre estas esferas en juego izquierdas, movimiento obrero y sectores populares habrían sido sólo parciales. ${ }^{25}$ En general, la izquierda argentina no habría logrado triunfos electorales más allá de Buenos Aires en las primeras tres décadas del siglo, ni habría conquistado una presencia continua en el movimiento obrero. Más precisamente,

24 Como sucedió con otras disciplinas, también la historia se profesionalizó en Argentina por fuera de las universidades nacionales, a través de las actividades de pequeños centros de investigación financiados por fondos internacionales que cesarían comenzada la democracia. Encabezado inicialmente por Luis Alberto Romero, Hilda Sábato, Leandro Gutiérrez, Ricardo González, Juan Carlos Korol y Miriam Trumper, el PEHESA fue fundado en 1978 como programa del Centro de Investigaciones Sociales sobre el Estado y la Administración (CISEA) con un objeto de estudio bastante determinado: "la formación de un mercado laboral, los estándares de vida de la clase trabajadora urbana, la cultura popular y la conformación del movimiento obrero". Así como los integrantes del PEHESA anuncian su programa historiográfico en la revista Latin American Research Review, publican la traducción política hacia el presente de estas preguntas históricas en dos artículos de la revista Punto de vista (Buenos Aires, 1978-2008). Ver: PEHESA, "¿Dónde anida la democracia?, Punto de vista, n. ${ }^{\circ} 15,1982$, pp. 6-10; PEHESA, "La cultura de los sectores populares: manipulación, inmanencia o creación histórica", Punto de vista, n. ${ }^{\circ} 18,1983$, pp. 11-14; y PEHESA, "An Argentine Social-History Group", Latin American Research Review, Vol. $18, n^{\circ} 2,1983, p p .118-124$. En las décadas siguientes, varias generaciones de historiadores se formaron dentro de este grupo de investigación y desarrollaron trabajos sobre anarquismo: Mirta Lobato, Sylvia Saitta, Juan Suriano, y Ana Lía Rey.

25 Además de los textos programáticos mencionados en la nota anterior, pueden tomarse como estado de la cuestión del que parten estas investigaciones: Luis Alberto Romero, Libros baratos y cultura de los sectores populares, Buenos Aires, CISEA, 1986; Luis Alberto Romero, Los sectores populares urbanos como sujeto histórico, Buenos Aires: CISEA-PEHESA, 1988; Luis Alberto Romero y Leando Gutiérrez, "Los sectores populares y el movimiento obrero en la Argentina", Boletín del Instituto de Historia Argentina y Americada Dr. Emilio Ravignani, $n^{\circ} 3$, 1991, pp. 109-145. 
el socialismo no habría logrado construir vínculos estrechos con las asociaciones gremiales; el sindicalismo habría repulsado continuamente determinaciones ideológicas de las familias de izquierdas; el contacto del anarquismo con el movimiento gremial se habría circunscrito a la década del diez; y el del comunismo se habría vuelto relevante sólo en algunos momentos puntuales de la década del treinta; de manera que, en síntesis, desde este punto de vista, y en contraste con las versiones en curso consideradas excesivamente políticas, los "sectores populares" del período 1880-1945 habrían sido mayoritariamente moderados.

Según esta perspectiva, la noción de trabajadores o movimiento obrero organizado "excluye a otros sectores" y recorta metonímicamente el todo por la parte. Por ejemplo, los trabajos de Bilsky no dejarían de buscar la conformación de una clase predefinida desde preguntas erradas. De modo que se trataría de un enfoque compartido con los llamados historiadoresmilitantes que no partirían de una contextualización correcta dentro de la historia político-económica. Además, L.A. Romero señalaba que específicamente la idea de la conformación de una clase fue utilizada aquí de modo meramente especular con lo sucedido en Inglaterra y que, en cambio, la experiencia local no ameritaría más que una relación esporádica y débil con el movimiento obrero organizado. ${ }^{26}$ La hipótesis era clara: "El rasgo más notable de la sociedad de Buenos Aires, la fuerte movilidad y la expectativa generada por ella, más fuerte aún, conspiró contra la constitución de identidades de clase firmes y consistentes", es decir, al menos en Argentina, las investigaciones anteriores se habrían esforzado en buscar un "sujeto teórico" concebido de antemano. Este texto "Los sectores populares como sujeto histórico" entrañaba problemas conceptuales e historiográficos no menos significativos que el de clase social. Por un lado, si bien se los reconoce como agentes históricos, se les rechaza la necesidad de una definición precisa en tanto se quiere considerar a estos actores como un fenómeno dinámico y procesual. La noción se vuelve tan amplia que termina por definirse por todo aquello lo que está en oposición de las élites. Y en la medida en que no resulta posible asignarle entonces tampoco identidad, la conclusión del propio texto es negativa, y en definitiva no se los reconoce como un sujeto sino como un "área de la sociedad". ${ }^{27}$

26 Esta línea de indagación dentro de la historia social que busca poder abordar a los sectores populares urbanos fuera del movimiento obrero organizado y las izquierdas sigue siendo desarrollada desde la Universidad de San Andrés en donde se asentó L.A. Romero durante la década del 2000. Ver: Roy Hora, "Izquierda y clases populares en la Argentina, 1880-1945", Prismas, n²3, 2019, pp-. 53-75; Roy Hora, "Trabajadores, protesta obrera y orden oligárquico, 1880-1900", Desarrollo económico, Vol. 59, n. ${ }^{\circ} 229$, pp. 329-360. En buena medida son textos que parten de referencias similares de la historia económica actualizada para sostener la existencia de un proceso integracionista exitoso, con relativamente buenos salarios reales, una movilidad social ascendente y canales de diálogo para sus reclamos. Desde este punto de vista, la atención brindada por la historiografía al movimiento obrero más rebelde resultaría excesiva.

27 A lo largo de estos textos programáticos, las referencias teóricas más bien asistemáticas mencionan la obra de marxistas ingleses,
Como es sabido, el programa proponía observar cómo variaron los indicadores de higiene, salud, educación y cultura de los sectores populares, para conocer sus condiciones de vivienda, sus condiciones de salud, sus prácticas culturales, etc., sin caer en análisis ideológicos o gremiales. ${ }^{28}$ Como corolario, con este programa quedaba entonces justificado por qué desviar el foco de investigación de la izquierda y el anarquismo. De este modo, esta serie de textos establecían una fuerte argumentación metodológica y política de manera interrelacionada, totalmente a favor de la centralidad que tendría la historia social como base de otros desarrollos históricos. ${ }^{29}$

En relación con el marco de recuperación democrática de los ochenta, por su parte, los académicos locales dentro del arco de Las izquierdas como José Aricó, Juan Carlos Portantiero y Jorge Dotti centraron su atención en la historia del socialismo $y$, en particular, en la figura de Juan B. Justo. Con algunos de ellos, los historiadores del PEHESA compartieron cátedras, instituciones, revistas y espacios comunes. En cambio, los rivales directos de este programa historiográfico parecían ser dos. Por un lado, de manera general una concepción nacionalista y romántica asociada al pueblo peronista. Por otro lado, la ya mencionada

como Hobsbawm, Thompson y Stedman Jones. Sobre el uso de estos autores por parte del PEHESA y el desarrollo de la noción de "sectores populares" puede verse en Agustín Nieto, "Los usos de E. P. Thompson en la historiografía "argentina": un itinerario posible", Rey desnudo, n. ${ }^{\circ}$ 3, 2013, 370-391.

28 A su vez, estas preguntas por las condiciones de vida de los trabajadores habían sido iniciadas con anterioridad en los trabajos de José Pannetieri. Sobre todo, José Pannetieri, Los trabajadores, Buenos Aires. Jorge Álvarez, 1967. Como señaló Diego Roldán, de manera similar con lo sucedido en el campo inglés, en este punto se abrió una discusión entre, por un lado, una visión positiva de la conformación y modernización del Estado argentino con relación a la situación de los trabajadores contra, por otro lado, una versión negativa que destacaba las condiciones lamentables de vivienda como justificación de los reclamos. Desde ya, esta bibliografía producida por PEHESA suele asentarse sobre los trabajos previos que iban en la primera dirección: Roberto Cortés Conde y Ezequiel Gallo, La formación de la Argentina moderna, Buenos Aires, Paidós, 1967; y Roberto Cortés Conde, El Progreso Argentino, 1880-1914, Buenos Aires, Sudamericana, 1979. Ver: Diego Roldán, "La formación de los sectores populares urbanos en la historiografía argentina", Signos Históricos, n. ${ }^{\circ}$ 20, 2008, pp. 194-232.

29 Probablemente esté demás decir que esta línea de textos tomaría un papel importante dentro de un conjunto de trabajos más amplio sobre la historia argentina en general que tuvo varios objetivos, como argumentar a favor de la función modernizadora de la élite política del período 1880-1910, la integración en buena medida exitosa de grandes masas inmigrantes que encontraban aquí vías de desarrollo $y$, en definitiva, un éxito económico y social de integración que llegaría hasta 1930.Como es sabido, a partir de 1989, la colección "Historia y cultura" de Sudamericana dirigida por Luis Alberto Romero fue la gran difusora de estos trabajos que se convirtieron en verdaderos clásicos y obras de referencia obligadas de la historiografía local. Por ejemplo, entre ellas, Leandro Gutiérrez y Luis Alberto Romero, Sectores populares, cultura y política, Buenos Aires, Sudamericana, 1995. Juan Carlos Torre, La vieja guardia sindical y Perón, Buenos Aires, Sudamericana, 1990; Daniel James: Resistencia e integración: 1946-1976, Buenos Aires, Sudamericana, 1990. En esta línea, Hilda Sábato finalmente cerraría una serie de estudios sobre el mercado laboral centrado en el siglo XIX: Hilda Sábato, Los trabajadores de Buenos Aires: la experiencia del mercado 1850-1880, Buenos Aires, Sudamericana, 1992; Hilda Sábato y Luis Alberto Romero, Los trabajadores de Buenos Aires: La experiencia del mercado, 1850-1880, Buenos Aires, Sudamericana, 1992. 
historiografía obrera de Edgardo Bilsky y Alberto Pla, y en menor medida la de Ricardo Falcón quien, sin embargo, compartía y participaba de proyectos y grupos de estudio en común con los miembros del PEHESA. De hecho, hacia fines de los años ochenta, fueron sobre todo los dos primeros quienes respondieron a esta reconocida discusión sobre el objeto de estudio que también obtendría futuros intercambios. ${ }^{30}$

De hecho, en contraposición a la línea de indagación del PEHESA, Alberto Pla fundó en Rosario el Centro de Estudios de Historia Obrera (CEHO) en 1991 en el marco de la Universidad Nacional de Rosario. Su figura fue luego permanentemente reivindicada por los nuevos exponentes de una cierta historiografía marxista como el historiador que poseía todos los créditos académicos, había editado colecciones de amplio alcance y, a la vez tenía, visión y proyecto militante. Alrededor de este espacio se formaron jóvenes investigadores de la Universidad Nacional de Rosario como Cristina Viano, Gabriela Águila y Gustavo Guevara, además de sus vínculos con Pablo Pozzi y otros historiadores emergentes de la Universidad de Buenos Aires.

Dentro de la misma Universidad rosarina, desde fines de la década de 1980, Ricardo Falcón creó también sus espacios de investigación sobre este arco temático alrededor de su cátedra, en donde se formaron, entre otros, Agustina Prieto y Alejandra Montserrat. Si bien en algunos puntos los intereses de investigación de este grupo parecerían cercanos a los de Pla en tanto también centraban en el movimiento obrero y la clase trabajadora en alguna medida funcionó como un espacio rival, más afín a los intereses teóricos y políticos del PEHESA

30 En buena medida, el objeto de estudio que resultaba relevante era un punto acordado: "el trabajo urbano". En la anterior nota, mencionamos los textos a tener en cuenta dentro de PEHESA que terminaban argumentando a favor de la noción de sectores populares. En la otra vereda, desde 1986 pueden registrarse las primeras respuestas y discusiones. En un primer momento, durante la década del ochenta. Ricardo Falcón, "Problemas teóricos y metodológicos en la historia del movimiento obrero en Argentina", en Carlos Zubillaga (comp.), Trabajadores y sindicatos en América Latina, Montevideo, CLACSO, 1989; Alberto Pla, "Apuntes para una discusión metodológica: clases sociales o sectores populares", Anuario de la escuela de Historia, n¹4, 1990, pp. 7-40; Juan Carlos Torre, "Acerca de los estudios sobre la historia de los trabajadores en la Argentina", Anuario del IEHS, n. ${ }^{\circ} 5,1990$, pp. 111-130. En su estado de la cuestión Ronaldo Munck reconoce el impulso reciente de la historia del movimiento obrero y que efectivamente faltan acercamientos desde la historia social que revisen problemas vinculados a la vivienda y la salubridad. Ronaldo Munk; "Labor Studies in Argentina", Latin American Research Review, Vol. 21, $n^{\circ} 3,1986$, pp. 224-230. El segundo momento se dio a partir de 2007: Hernán Camarero, "Consideraciones sobre la historia social de la Argentina urbana en las décadas de 1920 y 1930: clase obrera y sectores populares", Nuevo Topo, n. ${ }^{\circ}$ 4, 2007, pp. 35-60; Ezequiel Adamovsky, "Historia y lucha de clase: repensando el antagonismo social en la interpretación del pasado", Nuevo Topo, n 4, 2007, pp. 733; y Diego Roldán, "La formación de los sectores populares urbanos en la historiografía argentina", Signos Históricos, n. ${ }^{\circ}$ 20, 2008, pp. 194-232. En estos textos, por ejemplo, se entiende que en el conjunto de la producción de PEHESA, que va de Romero a Suriano, se atenta directamente contra la noción de clase, más allá de lo que propusieron los marxistas ingleses que dicen seguir, para asentarse en la idea de experiencia y cultura de los sectores populares. de Buenos Aires. Desde allí, Falcón participó de varios de los proyectos colectivos del grupo de estudio sobre sectores populares y movimiento obrero que funcionaba en Buenos Aires junto a Juan Suriano y Mirta Lobato, entre otros y de los encuentros del Club de Cultura Socialista de Rosario. ${ }^{31}$

Además, desde 1993, como una escisión del el Centro de Investigación en Ciencias Sociales (CICSO), Nicolás Iñigo Carrera organizó el Programa de Investigación sobre el Movimiento de la Sociedad Argentina (PIMSA). Más allá de las definiciones casi metafísicas de las que partió el programa, los trabajos publicados en la revista homónima PIMSA (Buenos Aires, 1997) buscaron generar una re-identificación de las clases sociales en diferentes períodos de la historia argentina a través de un seguimiento minucioso de los conflictos sociales en la prensa periódica de hecho, la práctica ya histórica proveniente de los fundadores de $\mathrm{CICSO}^{32}$ Con esta práctica asentada de recolección de datos capaces de ilustrar los momentos de conflicto, en líneas generales, eran trabajos que procuraban mantener una teoría fuerte de la clases sociales sin responder a las críticas sobre por qué éstas resultarían sustanciales en relación a sus niveles de conciencia, en momentos en donde distintas concepciones del trabajo se multiplicaron incluso desde el marxismo mismo. ${ }^{33}$

En definitiva, cada una de las líneas de investigación dirigieron acusaciones cruzadas sobre la existencia de presupuestos teleológicos, o bien señalando que las interpretaciones marxistas estaban sesgadas por la búsqueda de la conformación de una clase obrera, o bien, desde el otro lado, de estar sesgadas por la afirmación de una modernidad democrática y liberal integracionista. ${ }^{34}$ En esta última dirección, efectivamente, a nivel internacional, el gesto epocal, propio de las décadas del ochenta y el noventa, afirmaba la clausura definitiva del ciclo de las alternativas de izquierda en el país y en el mundo.

En lo que se refiere más específicamente a las discusiones sobre

31 Sobre su recorrido, puede verse el dossier publicado tras su fallecimiento en Estudios Sociales, n. ${ }^{\circ}$ 40, 2011

32 Probablemente el trabajo de mayor aliento y repercusión haya sido: Nicolás Iñigo Carrera, La estrategia de la clase obrera: 1936, Buenos Aires, La Rosa Blindada, 2000; donde contra una "verdadera campaña de guerra psicológica" que se suponía propia de los noventa se planteaba una definición fuerte de las nociones de clase, conciencia, fuerza social, estrategia, etc

33 Con posterioridad, entre quienes investigaron de manera cercana a este grupo están Jorge Podestá, María Isabel Grau, Analía Marti, Gustavo Contreras y Agustín Nieto. Además, luego compartieron actividades de investigación con la plataforma alrededor del Centro de Estudios de Historia los Trabajadores y la Izquierda (CEHTI) y la revista Archivos (Buenos Aires, 2014-).

34 También dentro de la oposición historiográfica trotskista puede mencionarse la revista Taller (Buenos Aires, 1996-2003), con un comité editor constituido por: Andrea Andújar, Márgara Averbach, Patricia Berrotarán, María Alba Bovisio, Hernán Camarero, Dina Edelmuth, Gabriela Farrán, Patricia Funes, Mónica Gatica, Susana López, Marisa Pineau, Pablo Pozzi, Andrés Reggiani, Alejandro Schneider, Analía Siri, Susana Taurozzi, Celia Trigueros de Godoy, Luciana Zollo. 
La experiencia anarquista, más recientemente, tanto Andreas Doeswijk como Hernán Camarero y Agustín Nieto criticaron la despolitización que involucraría el modo de aproximación a través de los sectores populares que había impulsado el PEHESA. ${ }^{35}$ Además, de distinta manera estos autores hicieron extensiva esta crítica al proyecto de L. A. Romero también a los trabajos posteriores de Juan Suriano producidos durante la década del noventa. De hecho, porque, como miembro de la generación más joven del PEHESA, en su tesis doctoral dirigida por L. A. Romero que años después dio lugar al libro Anarquistas del 2001 "sectores populares" fue finalmente una de las nociones utilizadas. ${ }^{36}$

(h) Si bien todavía no contamos con trabajos sobre la reconfiguración del campo de estudios en estas décadas, podemos decir que, en general, el proyecto de la revista Entrepasados (Buenos Aires, 1991-2012) continuó sólo parcialmente la línea de indagación propuesta por L.A. Romero y Gutiérrez. Dentro del PEHESA, las referencias al marxismo inglés eran compartidas explícitamente por la generación más joven de Juan Suriano y Mirta Lobato, quienes se desempeñaron respectivamente como becarios y ayudantes de las cátedras de L.A. Romero y Sábato y fueron parte de la operación de instalar el PEHESA dentro de la Facultad de Filosofía y Letras de la UBA durante la década del ochenta. Dentro de Entrepasados, estos dos últimos historiadores consideraban que el uso de $\mathrm{E}$. P. Thompson por parte de Romero resultaba en gran medida retórico. El texto más programático de la revista se autoinscribía como la generación más joven del ciclo de profesionalización de la historia con el objetivo de atender de manera amplia a los distintos aspectos del trabajo, fuera de las "visiones esencialistas de la clase obrera" y enmarcándose en los problemas de la "nueva historia social". De este modo, nuevamente reconocía la centralidad de la historiografía marxista inglesa producida durante la década del setenta y que precisamente definiría un cuerpo de problemas "más heterogéneo en torno a los sectores

35 Hernán Camarero, "Observaciones historiográficas sobre el anarquismo en los orígenes del movimiento obrero argentino, a partir del regreso de un clásico", en: laacov Oved, El anarquismo y el movimiento obrero en Argentina, Buenos Aires, Imago Mundi, 2013, pp. 1-15; Lucas Poy, "Introducción", Los orígenes de la clase obrera argentina, Buenos Aires, Imago Mundi, 2014. Según este último texto de Poy, en su revisión historiográfica de 2006, Juan Suriano habría discutido su propia decisión metodológica y habría dado más importancia a los límites de la noción de "sectores populares" a favor de reconocer más utilidad al de "clase obrera". Para una crítica en esta dirección específicamente al trabajo de Suriano, ver los textos citados de Agustín Nieto.

36 Como refiere Roldán al reconstruir esta polémica, un año antes de la publicación de Anarquistas, Suriano había afirmado: "Cuando en 1988 constituimos el Grupo de Trabajo sobre Movimiento Obrero y Sectores Populares nos planteamos debatir problemas teóricos y metodológicos referidos a la historia de los trabajadores y de los sectores populares en general. La elección del nombre del grupo reflejaba las líneas de trabajo existentes en su seno y, de algún modo, ellas estaban conectadas con una lectura crítica de la noción de clase y una insatisfacción con los modos de hacer historia de los trabajadores". Ver: Diego Roldán, "La formación de los sectores populares urbanos en la historiografía argentina", Signos Históricos, n. ${ }^{\circ} 20,2008$, pp. 194-232. populares y su experiencia". ${ }^{37}$

Con todo, al tratarse de una revista generacional más amplia, dentro de Entrepasados convivieron otras líneas de indagación; con Leticia Prislei y Patricio Geli, orientados a lo que en aquel momento se llamaba historia de las ideas desde la cátedra de Oscar Terán, y dentro de ésta tomando como objeto de estudio la izquierda socialista y anarquista de principio de siglo; con Silvia Finocchio, que se especializaba en enseñanza de la historia; con Ema Cibotti dedicada a la historia social de la inmigración; con Fernando Rocchi, orientado a una historia económica modernizadora e integracionista que se enfocaba en el consumo; y Gustavo Paz que se dedicaba a la historia colonial y la etnohistoria.

Se trató de una revista resistida por la comunidad/corporación de historiadores en tanto estaba impulsada por graduados no consagrados de ninguna manera y se posicionaba como alternativa dentro de la UBA al más tradicional Boletín del Instituto de Historia Argentina Dr. Emilio Ravignani (Buenos Aires, 1956-). De todos modos, se constituyó en una de las primeras revistas históricas sobre el tema con artículos que hoy forman parte de muchas currículas universitarias, sobre socialismo, anarquismo, historiografía, historia oral, "sectores populares" e "historia de Las mujeres", con traducciones de textos de Eric Hobsbawm, E. P. Thompson, Carlo Ginzburg, Roger Chartier y Nancy Fraser, además de reseñas y entrevistas. Si bien entonces claramente la revista Entrepasados se posicionaba a la izquierda de las otras publicaciones destinadas al público universitario dedicado a la historia, resultó moderada, en tanto en sus páginas no se entablaron mayores debates y su gesto inicialmente disruptivo terminó por difuminarse con el correr de los números. En retrospectiva, la revista se estableció sin responder políticamente a quienes estaban estructurando jerárquicamente el campo y no participó en los debates claves que se dieron en el ámbito de estudios históricos o de la cultura. De hecho, en relación con lo dicho anteriormente, Oscar Terán observó que al no renovar de manera determinada sus inscripciones teórico-metodológicas, la revista no contaba con herramientas para ser capaces de desafiar a los "mayores".

Atendiendo a la producción que surgió de esta plataforma en formato libro, por un lado, este proyecto se materializó en una serie de estudios de Mirta Lobato sobre las mujeres en el mundo obrero. ${ }^{38} \mathrm{Y}$ además obviamente en el mencionado libro Anarquistas. Es cierto que se trata de una obra que evita

37 Ver: Mirta Zaida Lobato y Juan Suriano, "Trabajadores y movimiento obrero: entre la crisis de los paradigmas y la profesionalización del historiador", Entrepasados, n²/5, 1993, pp. 41-64.

38 Probablemente con un proyecto todavía más claramente thompsoniano la publicación de su tesis doctoral también fue en 2001: Mirta Zaida Lobato, La vida en las fábricas (1904-1970), Buenos Aires, Prometeo, 2001. 
decisiones metodológicas y funciona en relación con la inercia de preguntas e intereses recién mencionados, propios de la línea pehesiana dentro de Entrepasados. Principalmente, se enfoca en aspectos de la sociabilidad libertaria con una propuesta de comprensión amplia sobre todo enfocada en captar al anarquismo de esos años como cultura política. De hecho, esta última fue otra de las nociones thompsonianas presente en textos traducidos en Entrepasados, a lo que se sumaba como referencia la investigación sobre el tema que se había realizado recientemente en España sobre todo el trabajo de Lili Ltvak que tuvo un reconocido impacto dentro del grupo y los nuevos estudios que se enmarcaban en los que optaba por llamar "la cuestión social". ${ }^{39}$ Resulta entonces interesante señalar que esta oscilación desde la historia social entre movimiento obrero, sectores populares y mundo del trabajo se mantuvo entre estos términos, desde el primer grupo de investigación "movimiento obrero y sectores populares" hasta la posterior conformación del Núcleo de Historia Social y Cultural del Mundo del Trabajo dentro de la Universidad Nacional de San Martín. ${ }^{40}$

Junto al mencionado libro de Zaragoza, Anarquistas es el texto clásico sobre el tema y fue el trabajo a partir del cual se formó la generación posterior de investigadores. Al tratarse del libro más importante producido localmente ha sido también el que funcionó como prisma y medida, y en relación con el cual se discuten las categorías utilizadas y se toman como ilustrativos sus límites y sus periodizaciones ${ }^{41}$ Sobre todo, porque la obra tenía un gesto de clausura que el propio autor se esforzó en destacar. Él mismo dejó de lado la investigación sobre el tema, dedicó su esfuerzo posterior a la coordinación de una de las dos últimas obras enciclopédicas de gran aliento sobre la historia argentina y en el momento de su fallecimiento elaboraba una biografía de Alfredo L. Palacios ${ }^{42}$

39 El otro prisma clave que parece funcionar en la serie de trabajos de Lobato y Suriano en los años siguientes es el de "cuestión social", que refiere al "sistema salarial, las dificultades médico-sanitarias y de salubridad, la vivienda y la emergencia de instituciones orientadas a defender los intereses de los trabajadores". Con esto buscaba determinar, aunque sea parcialmente, una esfera de intereses distinta a la económica o a la política, pero también de la estrictamente gremial, para abarcar también problemas sociales relativos a "mujeres e indígenas" que solían quedar fuera de otros estudios. Ver "Introducción" en Juan Suriano (comp.), La cuestión social en Argentina, 1870-1943, Buenos Aires, La Colmena, 2000.

40 Ver: Juan Suriano, "Los dilemas actuales de la historia de los trabajadores", en Jorge Gelman (comp.), La historia económica argentina en la encrucijada, Prometeo Libros, Buenos Aires, 2006, pp. 284-307.

41 Agustín Nieto dedicó una crítica a este libro como artefacto condensador de las hipótesis en juego por PEHESA. Por su parte, Doeswijk, quien también señaló la despolitización del acercamiento, junto a María Miguelañez discutió los límites que encubría su periodización. Laura Fernández Cordero señaló la pervivencia de una concepción subsidiaría de la apuesta libertaria por la emancipación sexual al compartimentalizarla hasta volverla ausente. Ver: Nieto, Agustín, "Notas críticas en torno al sentido común historiográfico sobre el anarquismo argentino", A Contracorriente, Vol. 7, n³ 3, 2010, pp. 219-248.

42 Nueva historia argentina / Coordinación general: Juan Suriano; asesoramiento general: Enrique Tandeter. Buenos Aires, editorial Sudamericana. (i) También en el campo académico, a partir de la década del ochenta, aparecieron las primeras investigaciones sobre el anarquismo que se descentraron del movimiento obrero sin correrse necesariamente hacia la historia social del mundo del trabajo y se enfocaron en tres grandes áreas que ampliaron notablemente el arco de debates para interesarse en el feminismo, la educación y la literatura anarquista. Estas investigaciones encabezadas por Dora Barrancos, Jean Andreu, Maxine Molyneux y Eva Golluscio auspiciaban un momento historiográfico que perdura marcadamente hasta hoy en día ${ }^{43}$

Desde los primeros años de la década, Jean Andreu y Eva Golluscio dedicaron varios trabajos al teatro, la literatura y los circuitos literarios y culturales del anarquismo ${ }^{44} \mathrm{~A}$ la vez que descubrían una serie inmensa de revistas literarias libertarias hasta ese momento inexploradas, sus acercamientos consideraron al movimiento libertario como "contracultural" como señalaremos, otra categoría también discutida en las décadas siguientes, es decir como contrapuesto a una cultura hegemónica. De este modo, un objeto de estudio hasta ese momento considerado subsidiario como las revistas comenzaba a encontrar un primer momento de atención por parte de los estudios literarios. Con posterioridad, esta se convertiría también en una de las líneas más exploradas ${ }^{45}$

Por su parte, los trabajos de María del Carmén Feijoo, Maxine Molyneux y Dora Barrancos abrieron asimismo otra línea de indagación que se mostró constante y permanentemente productiva para los debates actuales ${ }^{46}$ Después del trabajo

43 Desde ya, se trataba de un marco de intereses comunes que comenzaban a desplegarse en una importante cantidad de revistas de la década del ochenta como Unidad (Rosario, 1982-1983), Brujas (Buenos Aires, 1982-2012), Cuadernos feministas (Buenos Aires, 1984), Alternativa feminista (Buenos Aires, 1985-1986), La escoba (Buenos Aires, 1985), Feminaria (Buenos Aires, 1985-2009), Boletín de mujeres en movimiento (Buenos Aires, 1986), hasta llegar a las primeras revistas académicas, Hiparquía (Buenos Aires, 1988-1999) y Mora (Buenos Aires, 1995-).

44 A partir de este momento, la investigación local funcionó de manera sincronizada con la de España. Sobre todo, a partir de: Musa libertaria: Arte, literatura y vida cultural del anarquismo español (1880-1913), Barcelona, Antoni Bosch, 1981; La mirada roja: Estética y arte del anarquismo español (1880-1913), Barcelona, Ediciones del Serbal, 1988.

45 Su primer texto de hecho se tituló de esta manera: Jean Andreu, "Contracultura libertaria en el Río de la Plata y Chile", en Hacia una historia social de la literatura, Giessen, Losada-Bremer Editores, 1983; Eva Golluscio de Montoya, "Círculos Anarquistas y Circuitos Culturales en la Argentina de 1900", Caravelle, n 46, 1986. Estas investigaciones se plasmarían finalmente en un libro de gran circulación: Jean Andreu, Maurice Fraysse, Eva Goluscio, Anarkos, Buenos Aires, Corregidor, 1990. A partir de este trabajo, la atención sobre la literatura libertaria en Argentina y Uruguay ha desperado un interés constante y un gran desarrollo en los estudios doctorales de Armando Minguzzi y Pablo Ansolabehere. Remitiéndonos, como nos propusimos, únicamente al formato libro: Pablo Ansolabehere, Literatura y anarquismo en Argentina (1879-1919), Rosario, Viterbo, 2011.

46 María del Carmen Feijóo, Las feministas, Buenos Aires, CEAL, 1982; Emilio Corbiére, "Las luchas femeninas en el discurso socialista y anarquista. 1910-1930", Centros de cultura popular, 1982; Maxine 
iniciático de María del Carmén Feijóo, fue Dora Barrancos quien no sólo publicó los artículos fundamentales sobre el tema sino, además, obras de largo aliento que resultan hasta hoy en día una referencia obligada. Por añadidura, estos trabajos de Barrancos tenían la considerable ventaja de ser de los pocos que trazaban diálogos y buscaban experiencias comunes de las que participaron conjuntamente socialistas, anarquistas y sindicalistas. De este modo, sus trabajos eligieron un recorte temático y transversal educación, ciencia, sexualidad que habrían conformado a las diferentes tradiciones de izquierda ${ }^{47}$ Estas preguntas compartieron espacios dentro del proyecto de historia social impulsado por Leandro Gutiérrez. Aunque como vemos a través de sus títulos y sus análisis, la autora no dejaba de conceder relevancia a la inscripción ideológica dentro de las izquierdas de los emprendimientos político-culturales considerados. Por eso, desde ese espacio el enfoque se corría de la pregunta por las condiciones de vivienda, sanidad y cultura de los sectores urbanos. Sobre esto, en retrospectiva, la autora agregaba otras referencias teóricas producto de su exilio en Brasil, sobre todo vinculadas a la epistemología francesa Callinghem y Foucault, la relevancia de su director de tesis doctoral Michael Hall en la Universidad de Campinas durante su formación y la producción historiográfica feminista que ya se reconocía como corriente desde principios de los noventa Joan Scott, Mary Nash, Martha Vicinus, Michelle Perrot y Sheila Rowbotham. ${ }^{48}$

En paralelo, durante la década del noventa, la figura de Osvaldo Bayer se estableció como gran divulgador capaz de iluminar distintos episodios de la militancia libertaria. Su inmensa cantidad de notas en periódicos se continuó con su creciente presencia en los medios audiovisuales, al punto tal que el anarquismo en los años noventa quedó fácilmente emparentado a su figura. ${ }^{49}$ De este modo, volviendo a las referencias más amplias sobre las imágenes sociales del anarquismo, en el trabajo al que nos referimos, Lucio Mafud determina dos tipos de producción

Molyneux, "No God, No Boss, No Husband: Anarchist Feminism in Nineteenth-Century Argentina", Latin American Perspectives, $\mathrm{n}^{\circ} \%$, Vol. 13, 1986; Mabel Bellucci y Cristina Camusso, "La huelga de inquilinos de 1907: El papel de las mujeres anarquistas en la lucha", Cuadernos del CICSO, n58, 1987; Dora Barrancos, "Anarquismo y sexualidad", en Diego Armus (comp.), Mundo urbano y cultura popular, Buenos Aires, Sudamericana, 1989.

47 Dora Barrancos, La educación racionalista en la Argentina (1900-1930), Buenos Aires, [s.n.], [1986]; Las experiencias educativas del frente político-gremial socialista (1890-1913), Buenos Aires, CONICET, 1987; Cultura y educación en el temprano sindicalismo revolucionario, Buenos Aires, [s.n.], 1990; Anarquismo, educación y costumbres en la Argentina de principios de siglo, Buenos Aires, Contrapunto, 1990; Educación, cultura y trabajadores (1890-1930), Buenos Aires. CEAL, 1991; La escena iluminada (1890-1930), Buenos Aires, Plus Ultra, 1996.

48 Ver: Ana Martín y Adriana Valobra (comp.), Dora Barrancos: antología esencial, Buenos Aires, Clacso, 2019.

49 Durante la década del ochenta y del noventa, además los libros sumamente reeditados de Bayer sobre los vindicadores anarquistas dieron lugar a conocidas sobre la evaluación posterior de la violencia política que se había dado durante los setenta. Ver: Osvaldo Bayer, Rebeldía y esperanza, Buenos Aires, Ediciones B, 1993. audiovisual que comenzó en los noventa y se extendió hasta después del 2000.50 Por un lado, un nuevo tipo de filmación artesanal realizada por los propios simpatizantes con el objetivo de registrar las voces de la generación militante anterior el mejor ejemplo sería Qué vivan los crotos (Poliak, 1995). Y, por otro lado, aquella recuperada por documentales para los canales estatales en donde la figura de Bayer fue sólo la entrada a un interés de las plataformas culturales kirchneristas. ${ }^{51}$ Dentro de esta última serie, el ejemplo más marcado sería la serie-documental de trece capítulos de una hora cada uno Ni dios ni amo (Pérez, 2015).52

$(\mathbf{j}, \mathbf{k}$ y l) Como señalamos en otras oportunidades, a partir de la década del dos mil, la amplitud de una nueva serie de trabajos quedó sin duda habilitada material e intelectualmente por una nueva disponibilidad documental que Argentina logró tan sólo hace unos veinte años. ${ }^{53}$ Las tacañerías de documentación a los propios becarios pasaron a ser un recuerdo oprobioso del pasado y la investigación sobre el anarquismo local ya no tenía que desarrollarse obligadamente en Amsterdam o Campinas. Esta condición material de disponibilidad favoreció además que el arco de aproximaciones metodológicas, preguntas, temas y enfoques se amplíe notablemente, con trabajos que pueden inscribirse en múltiples áreas y métodos: historia transatlántica, historia global, estudios transnacionales, análisis de revistas, estudios decoloniales, historia de libro y la edición, estudios de género,

50 Probablemente esté demás remarcar las plataformas de más largo aliento editadas desde el trotskismo más clásico y el comunismo no se interesaron por el anarquismo; me refiero por ejemplo a revistas como Debate marxista (Buenos Aires, 1993-1998) de Rolando Astarita o Razón y revolución (Buenos Aires, 1995-) de Eduardo Sartelli. Por su parte, el ya largo proceso de la revista y editorial Herramienta (Buenos Aires, 1996-), desarrolló desde un trotskismo amplio una cultura marxista que al calor de los tiempos históricos se interesaba por algunos textos autonomistas de John Holloway, Raúl Zibechi o Michel Löwy.

51 "Sin dudas la política comunicacional del kirchnerismo fue determinante en ese cambio de paradigma, ya que al otorgarles un espacio destacado a historiadores, periodistas y filósofos progresistas o de izquierda con el fin de analizar la historia argentina (Pigna, Di Meglio, Feinmann, Halperín, Bayer), el anarquismo, junto a otras corrientes políticas populares, fueron objeto de revalorización", Lucio Mafud, "Las representaciones del anarquismo en la cultura audiovisual argentina", op. cit., p. 397.

52 También desde el 2000 es posible registrar un ensayismo libertario a cargo de Christián Ferrer que se desarrolló en paralelo al ámbito académico. Inicialmente a partir de las revistas porteñas Utopía (1984 1987), Farenheit 450 (1986-1988) y La letra A (1990-1993), publicó los dos tomos de El lenguaje libertario que marcaban un interés teórico por el anarquismo en diálogo con nueva filosofía francesa. El gesto consistió en correrse de la perspectiva histórica y recoger textos de una enorme diversidad de autores, en donde, a aquellos cercanos con el pensamiento libertario Fernando Savater, Paul Feyerabend y Cornelius Castoriadis, se sumaban textos de autores francamente ajenos del ámbito local, como Tomás Abraham, Horacio González y Héctor Schmucler. Ver: Christian Ferrer, El lenguaje libertario, Montevideo, Nordan Comunidad, 1991. En general, luego de este libro, su producción ha sido más bien asistemática en cuanto temas y modos de aproximación, aunque en su conjunto sus textos mantienen un interés constante por la cultura libertaria.

53 Ver Lucas Domínguez Rubio, "Los acervos documentales del anarquismo argentino", Revista General de Información y Documentación, Vol. $27, n^{\circ} 1,2017$, pp. 45-64. Entre otras cosas, aquí desarrollo cómo se conformaron los fondos documentales de la Federación Libertaria Argentina organizado por el grupo Biblioteca-Archivo de Estudios Libertarios, la compra de microfilms del IISH por parte del CeDInCl, la aparición de nuevos catálogos de consulta, etc. 
historia gremial, historia intelectual, itinerarios biográficos, historia regional e historia oral, entre algunos otros..$^{54}$

En general, la imagen cultural y política del anarquismo que comenzó a predominar se reconstruyó a partir de la crisis del marxismo y la aparición de nuevos debates dentro de los movimientos de izquierda que desde perspectivas neomarxistas y libertarias se interesaron por diferentes tipos de indagaciones sobre el autonomismo y la autogestión, sobre todo a partir de lecturas provenientes de Italia y Francia. En concordancia, en todo Occidente, la década del noventa ha sido el momento en que las luchas clásicas de la izquierda fueron embanderadas por movimientos sociales que, sin adscripciones políticas determinadas, ya no orientaron su esfuerzo a un cambio sistémico absoluto, sino que pretendieron organizarse a favor o en contra de demandas más específicas y de una manera predominantemente antijerárquica. Son muchos los textos que teorizaron con escasa historización este proceso a nivel global. $Y$ son muchos los que asistemáticamente propusieron distintas categorías para intentar abarcarlos, principalmente: autonomismo, anticapitalismo y autogestión. En cualquier caso, podemos a partir de estas propuestas afirmar al menos que se trata de la nueva y asentada cultura de izquierdas que se interesa sobre todo por nuevos modos de organización del trabajo, un desarrollo sustentable a diferentes niveles y distintos derechos individuales. Si bien sin embargo sólo algunos autores intentaron caracterizar estos movimientos como libertarios o anarquistas muchas veces simplemente porque resultaba difícil caracterizarlos como marxistas, probablemente sea éste el marco de preguntas desde el cuál se observa actualmente el pasado libertario.

Al mirar la Francia pos Mayo de 1968, ya en 1973 el mismo Hobsbawm reconocía que el desprestigio del régimen stalinista y la imposibilidad de un cambio revolucionario revitalizaban nuevamente un interés por el anarquismo que poco antes parecía imposible. Del mismo modo, también reconocía que el interés quedaba circunscrito al activismo de estudiantes e intelectuales. En el caso argentino, ya desde la experiencia 2001, los nuevos movimientos sociales y nuevos espacios culturales autogestivos fueron parte de este interés recargado.

De este modo, el hecho de descentrar el estudio del anarquismo del movimiento obrero recibió una nueva significación. En este marco, entonces, resulta claro cuál es el gesto trazado al revisar la producción historiográfica más reciente. En todos los casos se trata de investigaciones sobre los intereses libertarios que, con

54 Un panorama rápido puede trazarse, por ejemplo, al mirar los programas y las actas de los dos congresos de investigadorxs sobre anarquismos iniciados por Luciana Anapios, Laura Fernández Cordero y Fernanda de la Rosa que se desarrollaron en 2016 y 2019, respectivamente en Buenos Aires y Montevideo. A partir de las primeras cinco ediciones bianuales de las jornadas que los antecedieron, también surgió una amplia red internacional de inevestigadrxs sobre anarquismo. anterioridad, desde una visión marxista, se habían considerado meramente culturales. Ahora, en cambio, el anarquismo aparece como pionero en haber propulsado luchas sociales hoy todavía incumplidas, sobre todo por haber pensado la opresión no sólo como económica dentro de la fábrica, sino además dentro de la cultura, la familia, la pareja, la sexualidad, la salud y otras diversas esferas antes escasamente politizadas.

Con esto, no sólo existe una revalorización de las prácticas organizativas horizontales, sino, sobre todo, una necesidad de historizar el movimiento anarquista para encontrar el valioso yacimiento de los inicios de luchas vigentes: el feminismo y la emancipación sexual, ${ }^{55}$ la lucha por el aborto, ${ }^{56}$ el antimilitarismo, ${ }^{57}$ la educación, ${ }^{58}$ el cooperativismo, el ecologismo ${ }^{59}$ o el naturismo en su versión más política. ${ }^{60}$ Pero también este interés llevó a pensar las primeras experiencias de organización horizontales en distintos ámbitos; por ejemplo, en relación a los emprendimientos editoriales autogestivos que surgieron en la Argentina post-2001 como contrapartida de la gran concentración editorial de la década anterior, ${ }^{61}$ en el teatro social itinerante, ${ }^{62}$ en la cultura autogestiva alrededor de los ochenta, los funzines y el do it your self, ${ }^{63}$ y actualmente en la inscripción política también asistemática de algunos movimientos activistas por las libertades digitales. ${ }^{64}$ Desde ya, esta caracterización

55 Laura Fernández Cordero, Amor y anarquismo, Buenos Aires, Siglo Veintiuno, 2016.

56 Nadia Ledesma Prieto, La revolución sexual de nuestro tiempo, Buenos Aires, Biblos, 2016

57 Por ejemplo, esta sigue siendo una importante línea de indagación en Paraguay, en donde el servicio militar sigue siendo obligatorio. Para el caso argentino, pueden verse los trabajos de Gisela Manzoni, por ejemplo: "Antimilitarismo y antifascismo: particularidades de la intervención pública de las anarquistas argentinas", Cuadernos del Sur - historia, n. ${ }^{\circ}$ 41, 2012, pp. 189-213.

58 Acri, Martín y María del Carmen Cáceres, La educación libertaria en la Argentina y en México (1861-1945), Buenos Aires, Anarres, 2011.

59 Por ejemplo, a nivel internacional: Derek Wall, The Rise of the Green Left: A Global Introduction to Ecosocialism, London, Pluto Press, 2010; Michael Löwy, Ecosocialism: a radical alternative to capitalist catastrophe, Chicago, Illinois, Haymarket Books, 2015.

60 En esta dirección: Sebastián Stavisky, "Médicos de sí mismos: medicina naturista, revolución social y éxodo de la ciudad en el anarquismo de Buenos Aires a comienzos del siglo XX", Ecopolítica, n. ${ }^{\circ} 16,2016$, pp. $2-25$.

61 Ver: Alejandro Schmeid y Nicolás Chávez, "La edición autogestiva en las editoriales anarquistas: un siglo del que abrevan las micropolíticas de la edición contemporánea", Actas II Congreso Internacional de Investigadorxs sobre Anarquismo(s), Montevideo, Universidad de la República, pp. 684-699.

62 Ver los trabajos de Carlos Fos: El teatro libertario y su acción pedagógica, Salamanca, Ediciones del Huerto, 1995, En las tablas libertarias: Experiencias de teatro anarquista en Argentina a lo largo del siglo xx, Buenos Aires, Atuel, 2010; Teatro obrero: una mirada militante, Buenos Aires, Atuel, 2013.

63 El trabajo más sistemático: Pablo Cosso y Pablo Giori (comps.), Sociabilidades punks y otros marginales, Buenos Aires, Tren en movimiento, 2015.

64 Ver: Lucas Domínguez Rubio, "Izquierdas, software e internet: una agenda invisible", Nómadas: revista crítica de ciencias sociales y jurídicas, Vol. $54, n^{\circ} 1,2018$. 
general es sólo una propuesta de lectura, que queda lejos de ser adjudicada a quienes llevan a cabo estas investigaciones.

Estas luchas que aparecen hoy en día como constitutivas de las culturas de izquierdas encuentran al menos en nuestro país una búsqueda constante de sus comienzos libertarios. Aunque, en comparación, también es cierto que, cada una de ellas se encuentra en gran medida atomizada, especializada y muchas veces desconectada. Sin dudas el militante integral ideal de los primeros socialismos parece ser una pretensión demasiada alta. Se trata de luchas con necesidades de intervención y concientización inmediata que a principio de siglo $\mathrm{XX}$ podíamos encontrar de corrido en las páginas de un mismo número de una revista anarquista $y$, hoy en día, se dan en buena medida desvinculadas entre sí. Por eso, insistimos, con la enorme diferencia histórica de que estas luchas politizaron actividades que con anterioridad desde la izquierda misma eran escasamente consideradas y se pensaban únicamente como propias del ámbito privado, por lo que el gesto de historizarlas suele involucrar una enorme crítica al marxismo y la centralidad de la economía y los medios técnicos de producción como esfera central de opresión. ${ }^{65}$ Más allá de la enorme diversidad de plataformas en la que se publicó este nuevo corpus de investigaciones, como vislumbró Hobsbawm este interés estuvo vinculado sobre todo a espacios universitarios. ${ }^{66} \mathrm{Al}$ punto tal que recientemente Uri Gordon propuso el término "anarcadémicos" francamente horrible para referirse con entusiasmo a este conjunto de intereses. ${ }^{67} \mathrm{El}$ impulso de estas investigaciones en un contexto político favorable se vio potenciada por la existencia de un acceso enriquecido a distintos

65 En relación con las coincidencias californianas en boga que hacen mención al segundo epígrafe, esto llevo a una vehiculización epocal mucho más sencilla capaz de actualizar estas luchas en formas de vida ya no anarcófilas sino filo-libertarianas: del individualismo librepensador al emprendedurismo meritocrático; del vegetarianismo al fitness-detox del naturismo anti-especista al vegeterianismo como una politización que muestra sensibilidad sin discutir el status quo e impulsa proyectos de "ONGs para sacar a los perros de las villas"; del amor libre como modo de transformación política a las guías de autoayuda para volcarse al poliamor; del ecologismo libertario al conservadurismo per se de la naturaleza; del cooperativismo autogestivo a los fablabs auspiciados por grandes empresas. En muchos de estos traspasos, lo que se perdió fue la conexión política misma entre estas luchas, hoy en gran parte autonomizadas, y, entonces también, a favor de las lecturas economicistas marxistas, es cierto, con una reflexión más interesada en sus vínculos con la modificación de los modos de producción. Efectivamente, estos valores de organización en torno a la autogestión y el horizontalismo también gozaban de éxito dentro de muchos tempranos think-tanks neoliberales, el nuevo liderazgo cool del managment empresarial y las coordenadas culturales de lo que se conoció como ideología californiana que hoy se embandera dentro de los modos de organización y evaluación meritócratas con la forma de una do-cracy: quien hace decide y emprenduristas. De hecho, para algunos, incluso en Argentina, el anarquismo nació en los años sesenta en los Estados Unidos y Robert Nozick reverbera como un Bakunin exitoso.

66 En un trabajo aún no publicado, Laura Fernández Cordero documentó la relación reciente para el ámbito local entre distintos tipos de trabajos académicos y el movimiento libertario como objeto de estudio.

67 Uri Gordon es de hecho uno de los autores que con entusiasmo ve actualmente el anarquismo vivo en todos lados: Uri Gordon, Anarchy Alive! Anti-Authoritarian Politics from Practice to Theory, London, Pluto, 2007. acervos documentales, una sistematización del financiamiento académico para las humanidades, el auge de estudio de revistas, catálogos y hemerografías y la confección de diccionarios biográficos. ${ }^{68}$

De manera un poco más precisa, en esta enorme dispersión de investigaciones, en lo que se refiere específicamente a la investigación en Argentina, fueron varias las plataformas que de manera más o menos sistemática desarrollaron y desarrollan investigación histórica sobre las izquierdas en general y el movimiento anarquista en particular. ${ }^{69}$

En buena medida, reconociendo la poca importancia de las izquierdas en la historia política y económica del país, desde su fundación en 1998 el CeDInCl demostró en cambio la relevancia que tuvo y tiene la cultura de izquierda en la conformación de centenas de colecciones editoriales, periódicos y revistas del campo intelectual argentino. Con la idea de cultura de izquierdas participaba de este núcleo de preguntas actuales sobre la presencia de las luchas de izquierda y se descentraba de la pregunta sobre sus vínculos con el movimiento obrero. En líneas generales, el enfoque metodológico de la producción de sus investigadores y su revista Políticas de la Memoria (Buenos Aires, 1998-) se establece dentro los distintos desarrollos de la historia intelectual con análisis de trayectorias personales, estudios de revistas, sociología de los intelectuales, trabajos sobre la historia y la edición, estudios sobre la producción cultural, trabajos de recepción, conocimiento de la cultura socialista romántica, políticas de conservación documental e historia del marxismo. ${ }^{70}$ Como marca común puede destacarse entonces un interés teórico por la discusión metodológica, una ampliación del espectro de estudio documental, la construcción de corpus compuestos de documentos que se venían considerando intrascendentes o menores, y el hecho de que de manera relacionada a su tarea como centro de documentación la mayoría de las investigaciones aquí enmarcadas se centran en una historia de los artefactos culturales entendidos como herramientas de discusión e intervención política.

Aunque hoy parezcan en buena media establecidos, este cambio y amplitud de perspectiva contiene mayores consecuencias

68 Horacio Tarcus (dir.), Diccionario biográfico de la izquierda argentina Buenos Aires, Emecé, 2007; y su actual versión en línea: http:// diccionario.cedinci.org

69 En el 2009 Omar Acha publicó su ya citada Historia crítica de la historiografía argentina. Esta obra propone una revisión interna de la producción histórica de cada familia de la izquierda y no hace, por así decirlo, una historia de la historiografía sobre las obras históricas que tomaron como objeto de estudio los distintos movimientos políticos. Por esto, la revisión sobre el tema se queda en lo que críticamente llama las "intuiciones históricas" del anarquismo y, por ejemplo, no revisa las obras de Oved, Zaragoza o Suriano.

70 Para una revisión más amplia del contexto en el que surgió y se desarrolló el proyecto del $\mathrm{CeDlnCl}$, ver: "Aniversario y balance: por una renovación de la agenda historiográfica de las izquierdas", Políticas de la Memoria, $n^{\circ} 18,2018$, pp. 7-14 
historiográficas que las reconocidas. Poner a las izquierdas como objeto de estudio, no sólo implicaba un descentramiento del objeto clásico del marxismo, sobre todo permitía reponer los diversos movimientos sociales en los cuales las izquierdas habían tenido una participación histórica indudable, e incluso que de diferentes modos las izquierdas mismas ayudaron a constituir, como el movimiento obrero, el movimiento estudiantil, los movimientos de mujeres, el movimiento feminista, el movimiento antifascista, el movimiento de derechos humanos y varios movimientos editoriales, artísticos y culturales. Claro que además involucraba un descentramiento de la historia clásica programas partidarios, congresos, índices de sindicalización, etc., para poner en diálogo la historia social, la historia política, la historia de la cultura, y entonces, vislumbrar espacios en donde las izquierdas estaban llamativamente ausentes, como, por ejemplo, la historia del libro y la historia intelectual. Dentro de la historia obrera, la crítica de los determinismos económicos de clase permitió reponer la acción militante tanto personal como colectiva. En este sentido, por ejemplo, un proyecto regional e internacional como el del Diccionario biográfico de la izquierda se enmarca también dentro de esta perspectiva historiográfica. ${ }^{71} U$ otro ejemplo, como señalamos durante el recorrido realizado, con anterioridad las revistas de la izquierda de la década del veinte interesaban sólo a las investigaciones que desde los estudios literarios se dedicaban a las vanguardias. Desde ya, en suma, no se tratan de procesos historiográficos que haya impulsado solamente el $\mathrm{CeDInCl}$, pero probablemente sí haya sido el espacio en donde se planteó de manera más programática. ${ }^{72}$

Este marco académico de estudios sobre izquierdas y anarquismo constituido por el CeDInCl, el mencionado grupo de investigación

71 En retrospectiva, puede pensarse que fue un programa que se constituyó a través de las investigaciones realizadas y sus enfoques metodológicos deben ser buscados en la investigación producida. Sin embargo, al mismo tiempo, la agenda de intereses y las revisiones de El rodaballo (Buenos Aires, 1994-2006) y las introducciones de los libros El marxismo olvidado y Marx en Argentina resultan indicadores indudables de la inscripción teórica del proyecto en el marco amplio de la historia intelectual. Ver: Horacio Tarus, El marxismo olvidado, Buenos Aires, El cielo por asalto, 1996; Horacio Tarcus, Marx en la Argentina, Buenos Aires, Siglo XXI, 2007.

72 En lo que refiere más específicamente al anarquismo, me toca destacar el libro ya citado Amor y anarquismo de Laura Fernández Cordero que analiza la prensa libertaria en torno a la emancipación sexual del anterior cambio de siglo y mi trabajo de recopilación documental El anarquismo argentino, que buscó poner el acento en algunos de estos mismos elementos: catálogos editoriales, bibliografías, hemerografías, historia del libro y la edición, trayectorias personales y fondos documentales. También está en proceso la investigación de Ivana Margarucci que desde una perspectiva transnacional aborda la experiencia anarquista en la región andina. Por último, dentro de las apuestas libertarias en procesos más amplios que con anterioridad no habían sido tenidos en cuenta, me toca destacar los trabajos en conjunto con Natalia Bustelo sobre el anarquismo en el movimiento estudiantil reformista: Natalia Bustelo y Lucas Domínguez Rubio, "Vitalismo libertario y Reforma Universitaria en el joven Carlos Astrada", Políticas de la Memoria, n. ${ }^{016}$, 2016, pp. 295310; Natalia Bustelo y Lucas Domínguez Rubio, "Radicalizar la Reforma universitaria: la fracción revolucionaria del movimiento estudiantil argentino (1918-1922)", Anuario Colombiano de Historia Social y de la Cultura, Universidad Nacional de Colombia, Vol. 44 jul.-dic. 2017, pp. 3162. fundado por Suriano en el Instituto de Altos Estudios Sociales (IDAES-UNSAM) y un nuevo conjunto de investigaciones sobre el tema fue entonces donde surgieron en el 2007 las Jornadas de Investigadorxs sobre anarquismos organizadas por Luciana Anapios, Fernanda de la Rosa y Laura Fernández Cordero, que tuvieron como continuación los dos congresos homónimos y el Programa de investigadorxs sobre anarquismo que coordinan Ivanna Margarucci y Laura Fernández Cordero.

Para tomar algún punto de inflexión en relación a las líneas que venimos siguiendo, podemos considerar los artículos ya citados en la revista Nuevo topo (Buenos Aires, 2005-2009) que se posicionaban en relación a la discusión entre sectores populares y clase trabajadora para plantear matices y aperturas. Si bien para gran parte de la comunidad de investigadores del campo se trataba de una discusión inconducente, esta reactualización de la polémica en la revista resulta enormemente relevante, porque con esto esta discusión se convertiría en el espacio de intercambios donde manifestar decisiones metodológicas, modos de politización y distinto tipo de definiciones historiográficas. ${ }^{73}$ Ezequiel Adamovsky, por ejemplo, a partir de allí, propuso una concepción histórica de clase entendida como "holística" capaz de incluir otras dimensiones de opresión y considerar el sistema de producción del capitalismo en sentido amplio, y no solamente en la función específica del obrero. Desde la perspectiva autonomista de un primer momento de su producción, los movimientos sociales parecen funcionar como una reivindicación de las bases, como actores que sobrepasan los proyectos de los partidos políticos que se posicionan como vanguardia, dirigiéndose de este modo a una comprensión amplia de lo popular en sus últimos libros.

Por otra parte, fuera de la línea de indagación que luego desarrollaron Adamovsky y Di Meglio, también a partir de esta última revista mencionada, puede rastrearse la reconfiguración de la línea de interpretación marxista en el recorrido de dos revistas que surgieron desde el trotskismo de la Facultad de Filosofía y Letras de la Universidad de Buenos Aires en un nuevo vuelco a la historia de las luchas obreras Trabajadores (Buenos Aires, 2011-2012) y su continuación Archivos del movimiento obrero y la izquierda (Buenos Aires, 2012-). Además, en 2016 estos investigadores constituyeron el Centro de Estudios Históricos de los Trabajadores y la izquierda (CEHTI), también dirigido por Hernán Camarero. Inscribiéndose críticamente en la mencionada línea de producción historiográfica de Pla y Falcón y compartiendo jornadas y eventos con el proyecto

73 Ezequiel Adamovsky, "Historia y lucha de clase: repensando el antagonismo social en la interpretación del pasado", Nuevo Topo, $n^{\circ} 4$, 2007, pp. 7- 33; Hernán Camarero, "Consideraciones sobre la historia social de la Argentina urbana en las décadas de 1920 y 1930: clase obrera y sectores populares", Nuevo Topo, n. ${ }^{\circ} 4,2007$, pp. 35-60. A partir de aquí, al año siguiente apareció el artículo ya referido: Diego Roldán, "La formación de los sectores populares urbanos en la historiografía argentina", Signos Históricos, n. ${ }^{\circ}$ 20, 2008, pp. 194-232. 
de N. Iñigo Carrera, como los títulos de estas plataformas lo indican, parten de una justificación actualizada del movimiento obrero considerada como central según su programa, no puede pensarse izquierdas sin movimiento obrero y movimiento obrero sin izquierdas para luego, en buena medida, aceptar la presencia accesoria, no estructural, de las luchas actuales de la izquierda antes mencionadas a las que poco antes menos que despreciaban. De este modo, la definición de un sujeto histórico vinculado a un lugar establecido dentro del sistema del trabajo considerado éste también de un modo bastante tradicional sigue presente. $Y$, en definitiva, lo que queda en discusión es la autonomía misma de la política y del campo intelectual en relación con los partidos y las organizaciones gremiales. ${ }^{74}$

Así, fue en este nuevo marco academizado de estudio de las izquierdas y los anarquismos en donde también se delinearon los distintos ejes temáticos que se encuentran actualmente en discusión: sobre su relación determinante con el movimiento obrero, sobre los límites temporales y geográficos en los que tiene sentido tomar a este movimiento político como objeto de estudio, sobre el modo de investigarlo aisladamente y sobre el modo de enlazarlo con luchas actuales vigentes.

\section{Recapitulación: ejes de discusión historiográfica sobre anarquismo local}

Una vez hecho este repaso para enmarcar las discusiones actuales, pueden establecerse cuatro ejes recientes de debate estrechamente relacionados que recorren los estudios sobre el anarquismo en Argentina. El cuarto eje se constituye a partir de lo que, en alguna medida, se trata de una discusión tácita mucho más amplia.

\section{(i) Anarquismo y movimiento obrero.}

En primer lugar, como señalamos, desde las iniciáticas recopilaciones de documentos y memorias de Diego Abad de Santillán hasta el libro ya clásico de laacov Oved y los trabajos de Pla, Falcón y Bilsky, el eje que resultó determinante para la historiografía del anarquismo giró en torno a su vínculo con el movimiento obrero. Al mismo tiempo, también quien haya querido estudiar el movimiento obrero del país quedaba obligado

74 En buena medida, esta discusión que buscaba definir un sujeto histórico privilegiado los grandes hombres, los pueblos, la clase obrera organizada, los trabajadores en general, el Estado, las elites minoritarias, los movimientos sociales continuó más cerca en el tiempo con esta polémica de larga data como contrafondo. Por lo general, las distintas indicaciones han intentado llevarla fuera del ámbito específico de la producción para incluir otros aspectos políticos y culturales de la dominación, por lo que por momentos se ha utilizado la noción de "sectores subalternos". Con todo, el límite parece ser cierta resistencia al menos considerar la posibilidad de discutir nuevas aproximaciones metodológicas, por ejemplo, vinculadas a los campos de preguntas producto del llamado ciclo de "giros", lingüístico, material, "traductivo". a decir algo sobre los libertarios locales, aunque muchos estudios no tuvieron mayores intereses en el anarquismo y sólo señalaban unos confusos y en buena medida olvidables inicios libertarios con sus referencias obligadas. Por el contrario, quienes propusieron un acercamiento bajo las categorías de sectores populares dejaron de lado el estudio específico de ideologías políticas de izquierda en general y por lo tanto también del anarquismo.

Como señalamos, la hipótesis marxista en juego era aquella que puede retraerse al menos hasta Marx mismo y, a nivel local, hasta Lallemant. El anarquismo sólo tuvo cierta inserción social en países especialmente "atrasados", en estadios todavía incapaces de generar un movimiento obrero organizado y moderno. Esto incluía una caracterización general del anarquismo como una ideología escasamente articulada, más bien una suerte de fuerza pasional e incapacitada para la comprensión de los procesos históricos y sus determinantes económicos. ${ }^{75}$

Frente a esto, paulatinamente los distintos estudios han mostrado que las "otras luchas", como las llamó Santillán, hoy en día pueden verse dentro del tipo de opresión amplia que propuso visibilizar, discutir y combatir el anarquismo. Como señaló Laura Fernández Cordero en el texto que venimos siguiendo, tanto Falcón como Suriano diagnosticaron que una "absorción del anarquismo por el movimiento obrero impediría capturar lo esencial de la experiencia anarquista, la cual se habría presentado bajo la forma más vasta de un movimiento cultural, político, ideológico y social". 76

Como conclusión en este punto, insistimos, la apuesta política del anarquismo fue precisamente politizar ámbitos considerados de una importancia política secundaria, así su historia toma hoy un nuevo relieve y según sus defensores comprenderla desde

75 Como señalé en otro trabajo, se trata de una autocrítica que surgió de algunos militantes anarquistas argentinos de la década del treinta. En buena medida, textos editados desde espacios libertarios también remarcaron la necesidad de discutir la supuesta importancia del estudio del anarquismo de su éxito dentro del movimiento obrero. Ver: Pablo Pérez, Juan Manuel Heredia y Hernán Villasenin, El trabajo cultural del anarquismo, Buenos Aires, BAEL, 2005.

76 Luego de su repaso historiográfico, Laura Fernández Cordero concluye que: "no se puede hablar de invisibilidad en el caso que aquí se presenta. Las publicaciones son accesibles, los indicios están a la vista, y su centralidad en el movimiento libertario ha sido demostrada por una sostenida producción académica. Si continúan siendo accesorios o apenas señalados es porque se construyen lógicas de lectura muy consistentes que, en algunos casos, tienden a priorizar la clase como un eje exclusivo de interpretación mientras que, en otros casos, aun abriendo el análisis hacia otros espacios, determinan que el género y la sexualidad son cuestiones cercanas aunque menores en la cultura y la política. En ambos casos, se trata de lógicas de lectura que consideraron el género y la sexualidad como elementos específicos que, en tanto tales, pueden ser apenas señalados, y eventualmente, recibir atención por parte de otros abordajes también específicos. Así, la fructífera línea de trabajo relacionada con el feminismo, la historia de las mujeres y los estudios de género fue integrada al campo de la historiografía como un aporte particular, o como un conjunto de estudios que se suman pero no transforman el modo en el que se venía leyendo el anarquismo". Fernández Cordero, Laura, "Historiografía del anarquismo en Argentina: Notas para debatir una nueva lectura", A Contracorriente, Vol. 11, n 3 , 2014 , p. 50. 
términos únicamente estructurales revela un nuevo tipo de "inconsciencia" y "atraso". Si bien entonces resultan claros los problemas de desvincular el estudio de estas luchas del estudio del movimiento obrero durante el período inicial entre 1890 y 1910, e incluso 1918 y 1923, resulta sumamente problemático mantenerlo más allá de estos límites. Lo que da lugar al siguiente eje de debates.

\section{(ii) Mitologías regionales y temporales.}

Efectivamente, el segundo eje de debate, también en alguna medida saldado, trató sobre las coordenadas espacio-temporales en las cuales resulta relevante o no historizar el anarquismo en el país. Básicamente con dos preguntas: ¿cuál es el sentido de observar el anarquismo en Argentina más allá del año treinta? ¿Cómo justificar el estudio del anarquismo en las provincias argentinas, o de hecho también más allá en países limítrofes? El mencionado libro de Zaragoza cerraba su estudio en 1902; el de Oved, en 1905. El tercer gran libro sobre el tema, el de Juan Suriano, argumentó fuertemente sobre por qué clausurar la relevancia política del movimiento anarquista en 1910. El recorte temporal era claro, la apertura democrática que significó la sanción de Lay Sáenz Peña y la mayor permeabilidad de los reclamos por parte del Estado fue el fin de las posibilidades de una apuesta política revolucionaria con la cual se identificaba al anarquismo, únicamente en su carácter de opositor gremial al Estado. Aparentemente al cerrar ese libro todavía Suriano no conocía la tesis defendida por Andreas Doeswijk en la Universidad de Campinas en Brasil en 1998, que recién se publicaría quince años después. En su trabajo, Doeswijk sistematizaba lo que Bilsky había vislumbrado, pero nunca escribió: el notable aumento de las bases anarquistas a partir de la llegada de las primeras noticias sobre Revolución rusa. Pero sobre todo la intensificación de un movimiento huelguístico con intensa presencia de anarquistas y anarcosindicalistas, vinculado a un clímax editorial de revistas, folletos y discusiones, hasta el punto de postular la existencia de un "trienio rojo argentino" durante los años de 1919-1921. Sin dudas, esta investigación valorizaba otra parte notable de los fondos de Santillán y Nettlau presentes en Amsterdam. ${ }^{77}$

De hecho, la tesis de Doeswijk debe ser reconocida entonces como el cuarto libro más contundente sobre el tema, no sólo por discutir las mitologías que aquí estamos puntualizando, sino por proponer un trabajo capaz de discutir integralmente la historiografía, con aproximaciones metodológicas variadas, hipótesis fuertes y un recorrido con preguntas que permitieron iluminar las vicisitudes del movimiento libertario desde su reconfiguración en 1917 hasta 1930. Vale aclarar, la investigación

77 En esta dirección, los trabajos de Luciana Anapios desarrollaron la investigación de más largo aliento sobre el anarquismo de entreguerras: "El anarquismo frente a una coyuntura crítica: movilización popular, violencia y opinión pública en Buenos Aires a fines de la década del '20", Mundos do Trabalho, 2011, Vol. 3, pp. 285-306. "Prensa y estrategias editoriales del movimiento anarquista en la Argentina de entreguerras", Anuario del Instituto de Historia Argentina, $n^{\circ} 16,2016$, pp. 1-20., de Doeswijk no sólo amplió las periodizaciones historiográficas sobre la izquierda general que dio lugar al menos a dos libros posteriores de otros autores sino incluso la periodización posterior de la historia intelectual y social.

Volviendo a la discusión específica sobre los límites espaciotemporales en relación a los cuáles resulta relevante historizar el anarquismo, al agrandar la escala, más tarde y con diferentes preguntas también María Miguelañez discutió está periodización en vistas a historizar un anarquismo transnacional, mientras Agustín Nieto, al achicar la escala, argumentó sobre las implicancias políticas dentro de esta periodización para interesarse por un anarquismo dentro del movimiento obrero afuera de Buenos Aires. ${ }^{78}$

En una dirección, al achicar la escala, con posterioridad los trabajos que quebraron el marco espacio-temporal inicial puntualizaron las experiencias libertarias que por lo general se dieron durante los años veinte en La Pampa, en Salta, Tucumán, Jujuy, Punta Alta, San Juan y Neuquén y, más tarde, en Mar del Plata. ${ }^{79}$ Lo cual llevó a problematizar la idea del anarquismo "argentino" como sinónimo muchas veces de anarquismo en Buenos Aires y Rosario. El centralismo de la región económicamente más productiva funcionó de manera solapada con la ausencia de documentación conservada del resto de las regiones para plantear la pregunta sobre cuán políticamente marginales fueron estas experiencias. Con esto se trata de esbozar una discusión no saldada, totalmente abierta, que requiere una justificación metodológica sobre cómo brindarle relevancia historiográfica a objetos de estudio periféricos desde la perspectiva centralista desarrollada hasta ahora.

Con una crítica a la clausura de la experiencia dentro de los estados-nación, al agrandar la escala, a nivel transnacional, la investigación se ha abierto mucho más para romper con los límites político-nacionales apoyándose en la afirmación del internacionalismo impulsado por el propio movimiento y la importancia de las redes generadas. ${ }^{80}$ De este modo, el esfuerzo en exceder el nacionalismo metodológico y en inscribir las historias nacionales en la perspectiva latinoamericana procuraba

78 María Miguelañez Martínez, "1910 y el declive del anarquismo argentino. ¿Hito histórico o hito historiográfico?", XIV Encuentro de Latinoamericanistas Españoles, Madrid, 2010. Agustín Nieto, "Notas críticas en torno al sentido común historiográfico sobre el anarquismo argentino", A Contracorriente. Una revista de historia social y literatura de América Latina, Vol. 7, n³ 3, 2013, pp. 219-248.

79 Jorge Etchenique, Pampa Libre, Bernal, UNQui, 2000; Agustín Nieto, Entre anarquistas y peronistas, Buenos Aires, Imago Mundi, 2018.

80 En esta dirección los últimos trabajos de Martín Albornoz recuperan nueva documentación para proponer lecturas del marco de persecución policial al anarquismo, por ejemplo: Martín Albornoz y Diego Galeano, "Anarquistas y policías en el atlántico sudamericano: una red transnacional, 1890-1910", Boletín del Instituto de Historia Argentina y Americana "Dr. Emilio Ravignani", 2017. 
ser otra forma de quebrar los lazos gremiales o partidarios. ${ }^{81}$

En general, así como el quiebre con el estudio puramente obrerista del anarquismo involucraba también quebrar los límites temporales, al mismo tiempo también permitió alejarse de la visión totalmente anti-sistema de la propuesta del anarquismo, y por esto romper con la siguiente mitología. ${ }^{82}$

\section{(iii) Mitología de la autonomía radical.}

El tercer límite no radicó tanto en discusiones explícitas sino más bien en dificultades propias de la tarea historiográfica acompañadas de una concepción fuertemente anti-sistema del anarquismo. La mayor parte de la bibliografía ha tendido a compartimentalizar el estudio de cada una de las vertientes de la familia de las izquierdas. Sólo la apelación más reciente a una serie de luchas y discusiones en común la "cultura de izquierdas" permitió exceder los abordajes más monográficos sobre el anarquismo, el socialismo, el sindicalismo, el comunismo y el trotskismo, poco atentos a los diálogos, las discusiones, los proyectos compartidos o disputados y los derroteros militantes transversales, por no hablar de los habituales derroteros ideológicos que emergieron en los estudios durante los últimos diez años, como los "comunistas liberales" de Ricardo Passolini, o los ya mencionados "anarco-bolcheviques". Si bien retóricamente puede tratarse de un problema saldado, no deja de ser un escollo al momento de cualquier análisis. En buena medida este límite fue consecuencia de la propia historia militante y la historiografía que se abocó a construir su retrato como producto de la interacción entre su ideología y su práctica que resultaría pura. También en buena medida esta imagen radical y aislada fue solidificada por sus rivales socialistas y comunistas, como Jacinto Oddone, Sebastián Marota y Rubens Íscaro. Con todo, fue algo que el desarrollo académico posterior estuvo lejos de desterrar, sin poder correrse de una mitología de la coherencia en búsqueda de un cuerpo ideológico estable.

De este modo, mientras los análisis biográficos tendieron al punto de vista de las almas bellas y los estudios globales a los enfoques "obreristas", todos recayeron en cierto encapsulamiento doctrinario. De hecho, junto al alma bella y el vindicador pone bombas, ésta es otra imagen que sobrevive: la de un tipo de militante con una convicción anacrónica y excepcional,

81 Ver: María Miguelañez, "Anarquismo argentino transnacional: cooperación y conflicto (1917-1940)", Documento de trabajo, 2012; Constance Bantman y Bert Altena, Reassessing the transnational turn: scales of analysis in anarchist and syndicalist studies, Oakland: PM Press, 2017; Ivanna Margarucci, "Repensando el anarquismo en América Latina: ¿del nacionalismo metodológico a un giro transnacional incompleto?", Revista Prohistoria [en prensa].

82 Personalmente intenté proponer una periodización del anarquismo local a través de sus ciclos editoriales, ver: Lucas Domínguez Rubio, "Del folleto Una Idea a Proyección: sobre las prácticas editoriales del movimiento libertario en la historia del libro en Argentina", en Horacio Tarcus (dir.) y Ezequiel Saferstein (ed.), Edición y revolución en Argentina, Buenos Aires, Ubu, 2021 sumamente particular, solipsista, imposible de ser pensada como partícipe de la sociedad, como trabajador, pareja, lector, consumidor, etc.; cuando los mismos documentos destacaron estas otras dimensiones. En esta dirección, Juan Suriano también llamó la atención sobre los estudios que quieren plantearlo como algo "absolutamente diferente", frente a trabajos que tendieron a englobarlo en una cultura o algo absolutamente radical que pretendían pensarlo en sus medidas extremas. En este sentido, como mencionamos, las investigaciones llevadas a cabo por Dora Barrancos destacaron los proyectos educativos comunes entre socialistas, anarquistas y sindicalistas; y Andreas Doeswijk subrayó la existencia de plataformas de colaboración en vista a la unificación de las federaciones obreras en curso hacia $1920 .{ }^{83}$ La renovación historiográfica apunta a justamente a reponer esas experiencias no como hibridaciones, sino como proyectos políticos que obligan a repensar los vínculos considerados entre anarquismo y librepensamiento, anarquismo y sindicalismo, entre anarquismo y bolchevismo, e incluso entre el anarquismo y el socialismo liberal o el anarquismo y las democracias de avanzada.

Sin duda, este quiebre historiográfico fuerte de las identidades políticas clásicas como inmutables en el tiempo y el espacio resulta fundamental para abarcar de manera más integral la historia del movimiento libertario. Todavía queda una enorme cantidad de trabajos pendientes sobre los vínculos entre los miembros del Llamado Grupo de Boedo, los Artistas del Pueblo y los libertarios filobolcheviques durante la década del veinte. ${ }^{84}$ En la misma dirección, las revistas de la década del treinta y el cuarenta ostentan una amplitud teórica en relación con la enorme cantidad de militantes de diversas trayectorias que pasaron por ellas. ${ }^{85}$ Los trabajos de Karina Jannello despuntan los vínculos desconocidos por la bibliografía y negados por la militancia entre el movimiento libertario, la Unión Democrática y la conformación de la Asociación por la Libertad de la Cultura en Argentina. ${ }^{86}$ En esta dirección, también resulta sugerente la actual propuesta de Roy Hora que busca afirmar la existencia de un anarquismo mesurado y dialoguista. ${ }^{87}$

\section{(iv) Mitologías y continuidades: autogestión, autonomismo,}

83 Para el mismo período, Horacio Tarcus había propuesto no el término "anarco-bolcheviques" sino "socialistas libertarios". Horacio Tarcus, "Revistas, intelectuales y formaciones culturales izquierdistas en la Argentina de los '20", Revista Iberoamericana, n² 208-209, juliodciembre de 2004

84 Como sostuve en otro trabajo, el hecho de que la cultura libertaria se conformó en diálogo con múltiples esferas sociales queda claro a partir de ver las bibliotecas libertarias conformadas por las donaciones de sus militantes, ver: "Introducción" en El anarquismo argentino, op. cit.

85 Osvaldo Graciano, "La escritura de la realidad. Un análisis de la tarea editorial y del trabajo intelectual del anarquismo argentino, entre los años 30 y el Peronismo", Izquierdas, Vol. 12, 2012.

86 Por ejemplo, Karina Jannello, "Benito Milla: un Ulises desgraciado", Catedral tomada, $n^{\circ} 11,2018$.

87 Ver: Roy Hora, "Izquierda, trabajadores y orden oligárquico, 1880-1900", Nuevo Mundo Mundos Nuevos, 2020. 
contracultura, activismo, sensibilidad libertaria y/o anticapitalismo.

Finalmente, esto último responde a un problema de definición conceptual difícilmente abarcable que se exacerbó en las últimas décadas a partir del mencionado contexto de reflexión teórica suscitado por la crisis del marxismo y la nueva y amplia reflexión sobre el autonomismo.

Excepto casos marginales, el anarquismo orgánico fue renuente a actualizarse además la transmisión transgeneracional prácticamente no existió, sin embargo, sus textos y experiencias se transformaron en "antecedentes" ineludibles, más allá de que los actores actuales recuperen o no explícitamente textos, nombres, nociones, conceptos y/o inscripciones determinadas a una tradición política, sino únicamente sus prácticas. ${ }^{88}$

Como conclusión queda entonces planteado un eje de discusión aún en curso sobre el cual radica la suerte de gran parte de las investigaciones actuales y todavía se están proponiendo las primeras hipótesis: ¿cómo pensar las continuidades de alguna manera inexistentes entre el movimiento anarquista y los actuales movimientos autogestivos que muchas veces retoman sólo asistemáticamente distintos elementos de diferentes tradiciones de izquierda? ¿Bajo qué conceptos historizar estos intereses comunes que se muestran tanto teóricos como prácticos? ¿Cómo traducir esas experiencias que Llaman la atención desde el presente sin achatar su experiencia histórica documentada? Como señalamos, las respuestas están en curso. Sin pretensiones de lograr exhaustividad, podemos internar determinar parcialmente y con muchas dudas algunas propuestas.

Al menos podemos proponer la siguiente enumeración sobre los términos con los cuales se pensó la importancia de historizar problemas actualmente relevantes.

(a) Las que podemos llamar recuperaciones activistas directamente no-históricas;

(b) otros estudios que buscan continuidad en las prácticas horizontales; ${ }^{89}$

(c) otros que desarrollan continuidades teóricas (por lo general desde referencias postestructuralistas); $; 0$

88 Quizás puede pensarse que existieron excepciones a nivel internacional, al menos en relación a ciertos autores puntuales: el proyecto de Rudolf Rocker en los años treinta y cuarente, Daniel Cohn Bendit en los sesenta, Daniel Guerin en diálogo con el luxemburguismo y el marxismo libertario, Mercier Vega a comienzos de los setenta, la síntesis de marxismo y anarquismo de Michael Löwy. Hasta el momento no existe un relevamiento exhaustivo de estos intentos de renovación doctrinaria.

89 En relación con los movimientos actuales de ocupaciones culturales, la nueva educación libertaria, el teatro independiente, las editoriales autogestivas, los movimientos antiglobalización y otras experiencias cooperativistas.

90 En esta dirección, numerosos trabajos han buscado continuidades (d) a través de algunos conceptos en curso, como el de autonomismo en su vertiente no marxista; ${ }^{91}$

(e) o en el más amplio de anticapitalismo; 92

(f) en términos de "una sensibilidad libertaria"93;

(g) o de hecho en la propuesta de pensar e historizar su devenir como parte de una cultura de izquierdas. Sirva al menos este listado para proponer algunas líneas orientativas a discutir. teóricas en la obra de muchos filósofos franceses, como Agamben, Derrida, Deleuze, Foucault, los desarrollos de Tiqqun y el Comité invisible. En menor medida algunos trabajos se han propuesta una antropología libertaria y/o conexiones con la teoría decolonial.

91 Ver, por ejemplo, Pensar las autonomías, México, Bajo tierra - Sísifo, 2011.

92 Ezequiel Adamovsky, Anticapitalismo: la nueva generación de movimientos emancipatorios, Buenos Aires, Era Naciente, 2004

93 Laura Fernández Cordero, Amor y anarquismo. Buenos Aires: Siglo XXI, 2016. 


\section{Resumen}

El presente artículo interroga las perspectivas historiográficas que se interesaron en la experiencia libertaria argentina para determinar los principales ejes de discusión que se trazaron entre ellas. Su objetivo principal consiste en comprender estas obras en un esquema historiográfico más amplio sobre las izquierdas en general. Para esto determina principalmente tres momentos. Uno fuertemente vinculado a las relecturas del anarquismo dentro de la llamada nueva izquierda. Un segundo momento propio de las décadas del ochenta y el noventa que afirmaba la clausura definitiva del ciclo de las alternativas de izquierda mientras las investigaciones que se desarrollaban fuera del país proponían un nuevo cúmulo de preguntas. $Y$ un tercer momento académico interesado por el pasado de las reivindicaciones de los derechos individuales, los modos de organización autogestivos y la politización histórica de la agenda anarquista, sobre el feminismo y la emancipación sexual, la lucha por el aborto, el anti-militarismo, la educación libre, el cooperativismo, el ecologismo y el naturismo.

Palabras clave: Anarquismo en Argentina; Historia de la historiografía; Historia de las izquierdas; Historiografía.

\section{Abstract}

The present article questions the historiographic perspectives that were interested in the Argentine libertarian experience in order to determine the main discussion that were drawn among them. Its main objective is to understand these works in a broader historiographic scheme about the left. For this purpose this article determines three moments. One is strongly linked to the readings of anarchism within the so-called new left. A second moment typical of the 1980s and 1990s that affirmed the definitive closure of the cycle of leftist alternatives, while the research that were being developed outside the country proposed a new set of questions. And a third academic moment interested in the past of the demands for individual rights, the self-organization and the historical politicization of the anarchist agenda, on feminism and sexual emancipation, the struggle for abortion, anti-militarism, free education, cooperativism, ecology and naturism.

Keywords: Anarchism in Argentina; History of Historiography; History of the Left; Historiography.

Recibido: 01/04/2020. Aceptado: 14/09/2020.

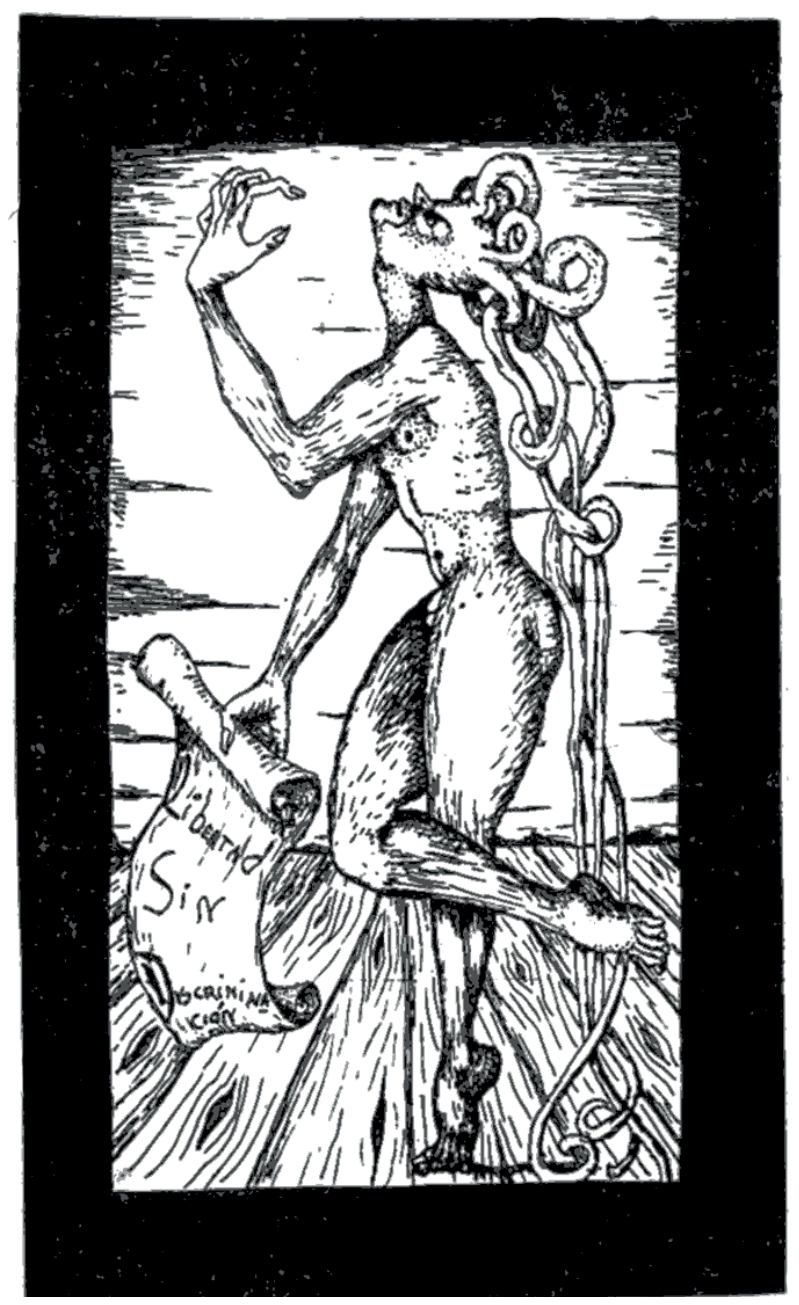

Marcelo Acosta [Marcelo Manuel Benítez]. Ilustración. En: Vamos a Andar, nº 11 (11/1988). 